\title{
Plankton food-webs: to what extent can they be simplified?
}

\author{
Domenico D’Alelio, "Marina Montresor, Maria Grazia Mazzocchi, Francesca Margiotta, Diana Sarno, \\ Maurizio Ribera d'Alcalà
}

Stazione Zoologica Anton Dohrn, Villa Comunale, 80121 Napoli, Italy

*Corresponding author: dom.dalelio@gmail.com

\begin{abstract}
Plankton is a hugely diverse community including both unicellular and multicellular organisms, whose individual dimensions span over seven orders of magnitude. Plankton is a fundamental part of biogeochemical cycles and food-webs in aquatic systems. While knowledge has progressively accumulated at the level of single species and single trophic processes, the overwhelming biological diversity of plankton interactions is insufficiently known and a coherent and unifying trophic framework is virtually lacking. We performed an extensive review of the plankton literature to provide a compilation of data suitable for implementing food-web models including plankton trophic processes at high taxonomic resolution. We identified the components of the plankton community at the Long Term Ecological Research Station MareChiara in the Gulf of Naples. These components represented the sixty-three nodes of a plankton food-web. To each node we attributed biomass and vital rates, i.e. production, consumption, assimilation rates and ratio between autotrophy and heterotrophy in mixotrophic protists. Biomasses and rates values were defined for two opposite system's conditions; relatively eutrophic and oligotrophic states. We finally identified 817 possible trophic links within the web and provided each of them with a relative weight, in order to define a diet-matrix, valid for both trophic states, which included all consumers, from nanoflagellates to carnivorous plankton. Vital rates for plankton resulted, as expected, very wide; this strongly contrasts with the narrow ranges considered in plankton system models implemented so far. Moreover, the amount and variety of trophic links highlighted by our review is largely excluded by state-of-the-art biogeochemical and food-web models for aquatic systems. Plankton models could potentially benefit from the integration of the trophic diversity outlined in this paper: first, by using more realistic rates; second, by better defining trophic roles of consumers in the planktonic web. We suggest that most trophic habits present in planktonic organisms must be contemplated in new generation plankton models.
\end{abstract}

Key words: Food-webs; grazing; plankton vital rates.

Received: November 2015. Accepted: May 2016

\section{INTRODUCTION}

Plankton is a morphologically, genetically and trophically diverse ensemble of both unicellular and multicellular organisms, whose individual dimensions span over seven orders of magnitude (Boyce et al., 2015). Their phylogenetic differences are larger than those of terrestrial organisms covering the same size range. The only reason why they are grouped together is that they live suspended in the water, without relying on any substrate which is not produced by them. Nevertheless, plankton is a fundamental player in the biogeochemical cycles in aquatic systems and constitutes the essential source of carbon ultimately feeding the larger metazoans living in the ocean (Behrenfeld and Boss, 2014).

The general perception is that plankton is undergoing important modifications in the oceans due to global change (Chen et al., 2012; Chust et al., 2014). Yet, those modifications are often elusive, probably because the knowledge on the cascading processes which regulate the plankton food-web is still scarce. Indeed, while a deeper and deeper knowledge is accumulating at the level of single species and single trophic processes, the overwhelm- ing biological diversity of plankton interactions is insufficiently known and only rarely, and partially, integrated within a coherent and unifying trophic framework (Boit et al., 2012). Yet, advisable studies on plankton communities should move towards holistic/system ecological approaches considering several, if not all, components of the food-webs and possibly highlighting the emergent properties which hint at the regulating mechanisms of a complex system as plankton. For emergent properties we refer to those relying on interactions among system's components that are not predictable by analysing the response of individual components in isolation. These properties revealed to be crucial in regulating pelagic communities at the level of macroscopic organisms via mechanisms driven by food-web organization (Link et al., 2015).

Food-web models should be seen at as networks including functional nodes (FNs), which, in turn, must be connected by trophic links. They should be based on a minimum number of nodes, thus impeding gross aggregations among taxa (Abarca-Arenas and Ulanowicz, 2002). For each node, a somewhat precise biomass value and vital rates, such as production, consumption and as- 
similation rates must be set. Moreover, network models should be developed starting from diet-matrices linking consumers and producers. The careful definition of nodes, their characteristics and 'roles' in the frame of a food-web must rely on trustable taxonomic data, such as those collected in long-term studies (Ribera d'Alcalà et al., 2004). On the other hand, food-web models need a thorough biological accuracy and their parameterisations are largely time-consuming, which is one of the reasons why they are so scanty. All the above requirements are usually not matched in models dealing with plankton: in these models, the web of trophic links, especially for what concerns unicellulars, is usually grossly parameterised and the modelled feeding processes focus on simple trophic steps including mainly metazoan herbivory (Flynn et al., 2013; Mitra et al., 2014). As a consequence, while a vast, though fragmentary and often redundant, literature for trophic rates of planktonic organisms has been accumulated in the past decades, works on detailed plankton food-webs are still lacking.

In this paper we provide a careful compilation of data suitable to build food-web models including plankton, with a major emphasis on coastal ecosystems. Although this paper does not present model approaches, the compilation provided herein can be useful to develop models of plankton focused on trophic interactions, such as model recently described by D'Alelio et al. (2016). Our selection aims at describing putative processes in a coastal marine system. To this end, we identified the main components of the plankton community at the Long Term Ecological Research Station MareChiara in the Gulf of Naples (LTER-MC). These components represented the functional nodes (FNs) of a virtual food-web and, for each of these, we derived biomass and attributed vital rates, reviewing a vast literature on plankton organisms, which is reported in the reference section. We finally selected trophic links in the web on the base of literature review. We remark the fact that our parameterization might not be applied to off-shore and deep-sea systems, although our study may provide general conceptual criteria also useful to developing of modelling studies. A further limit of our work is that we were not able to include macrozooplankton, which were not routinely sampled at LTER-MC, in our conceptual framework.

The overall scope of this exercise is to provide a set of values and illustrate a procedure that may be used as a reference for other modelling studies. Furthermore, we compare and discuss the extensive suite of rates with the more compact parameterizations used in biogeochemical and fisheries models. The compilation presented herein is focused on summer, which is a crucial period for ecological processes of particular interest for coastal management, such as the development of harmful algal blooms and the recruitment of small pelagic fish.

\section{METHODS}

\section{Study area and context}

The plankton food-web described herein is localized in the Gulf of Naples (GoN), a Mediterranean coastal embayment open to the Tyrrhenian Sea. Data of plankton species and groups and their biomasses were derived from the Long Term Ecological Research MareChiara (LTERMC, depth $=75 \mathrm{~m}$ ), at which sampling is routinely carried out since 1984 (Ribera d'Alcalà et al., 2004). The present study refers to the plankton community occurring at the above-mentioned site and described by a previous papers by our group (D'Alelio et al., 2015, 2016). The sampling was focused on unicellular plankton and mesozooplankton and it did not allow to effectively collect all juvenile stages of mesozooplankton - i.e., among copepods, copepodites and not nauplii were routinely harvested by the $200 \mu \mathrm{m}$ size mesh used (Ribera d'Alcalà et al., 2004). At the LTER-MC site, relatively eutrophic and oligotrophic states (herein Green and Blue) alternated during most of the Mediterranean summers (mid-June - late August, years 2002-2009) as an effect of the alternation between relatively coastal and offshore water displacement towards the monitoring station (D'Alelio et al., 2015) (Fig. 1).

\section{LTER-MC}

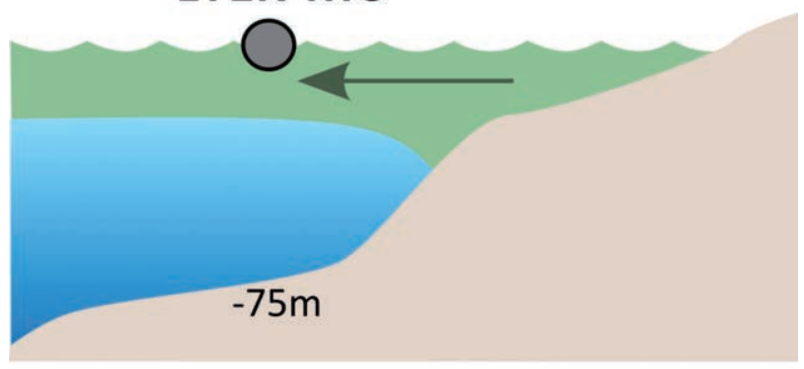

LTER-MC

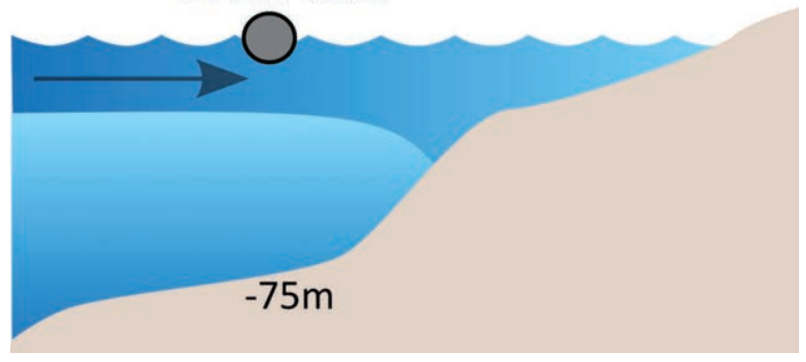

Fig. 1. The Green-Blue swing. The figure represents the intermittent horizontal displacement of surface waters $(0-5 \mathrm{~m})$ in the Gulf of Naples during summer, according to D'Alelio et al. (2015). The uppermost and lowermost panels indicate the arrival to LTER-MC station of waters from coastal or offshore areas, respectively. The Green water is richer in phytoplankton biomass than the Blue water. 
The conceptual food-web herein presented is assumed to occupy the first 60-meter of the water column, despite the slightly deeper bottom at the LTER-MC. Two reasons justified this choice: i) mesozooplankton at LTER-MC was sampled by means of vertical nets covering the water-layer spanning 0-55 $\mathrm{m}$ in depth (Ribera d'Alcalà et al., 2004); ii) we assumed that most trophic processes in the plankton occurred in the first $60 \mathrm{~m}$ of the water column, due to lowlight conditions and sediment re-suspension below that depth. Since the water column was divided by two main layers by a steep density-gradient in the coastal planktonic system that we studied in the GoN during summer (Ribera d'Alcalà et al., 2004), unicellular organisms in our casestudy were divided between surface and subsurface communities (from 0 to $-5 \mathrm{~m}$ and from -5 to $-60 \mathrm{~m}$, respectively). Yet, mesozooplankton and the protist Mesodinium rubrum (syn. Myrionecta rubra) were not separated between layers: in fact, these organisms are reported to perform large-scale diel vertical migrations across the pycnocline (Crawford, 1989; Stich and Lampert, 1981).

\section{Construction of the conceptual plankton food-web}

The biomasses for the nodes of the web were taken from D'Alelio et al. (2016), a former study in which the same food-web presented herein was investigated. They consist of average values (years 2002-2009, as in D'Alelio et al., 2015) for a two-layer water column at LTER-MC over a two-months summer period (July-August). Our analysis (in the present paper and in the parallel one, D'Alelio et al., 2016) tries to depict the typical pattern in carbon transfers within the analyzed food-web. Thus, we considered interannual variability as a second order term. In these works we used the POC available data (average values for summer of years 2007-2009) as a closure term, despite their reduced coverage ( 3 over 7 years). Each living $\mathrm{FN}$ is represented herein by a set of vital rates including a production rate (for all living organisms) and consumption and assimilation rates (for organisms featuring a heterotrophic metabolism). Vital rates are largely variable for any species, since they depend upon a wide spectrum of variables. For this reason, we provide a range of variability comprised between minimum and maximum values. Specific ranges are indicated for each of the two states of our case-study (i.e., Green and Blue).

Biomass data for web-nodes were not used to reproduce biomass fluxes across the web, since the latter option can be only pursued by means of appropriate calculations, such as those provided by a mass-balanced model approach that is out of the scope of the present work and has been the main goal of D'Alelio et al. (2016). Yet, individual biomass data were used to modulate size-dependent rates to ranges pertaining the organisms present in our study system; the total biomass of unicellular organisms was used to set consumption rates in consumers in case these were reported in the literature as dependent from food concentrations.

Primary production rates were used to corroborate production rates of primary producers. All the above-mentioned rates are expressed per unit of biomass (i.e., in $\mathrm{d}^{-1}$ units). As a general rule for microbes in the surface layer, the maximum values of production rate were taken from the literature, while the minimum values were derived by multiplying the maximum value of the range by the ratio between the minimum and maximum primary production rates detected in the surface layer $\left(\mathrm{T} \sim 25^{\circ} \mathrm{C}\right)$ and at the specific system's state (see next Methods section). Concerning the deeper water-layer in our study system $\left(5-60 \mathrm{~m}\right.$ in depth, $\left.\mathrm{T} \sim 15^{\circ} \mathrm{C}\right)$, the range of values of production rate for each unicellular FN (including auto-, mixo- and heterotrophic organisms) were derived analytically, i.e. by multiplying the minimum or maximum production rate of each $\mathrm{FN}$ at surface as derived from the literature by the ratio between the median primary production in the deeper layer and the median primary production in the surface layer. The latter choice stemmed from the assumption that production rates were correlated with the primary production of all phytoplankton in the deeper water-layer. Since diatoms in the deeper layer were represented by one and a single node (FN 30), the median values of minimum and maximum production rates of diatoms at surface (FN 4-10) were considered instead of the single value. Although laborious and indirect, the estimations derived from conceptual steps illustrated above provided production rates for unicellulars in the sub-surface water layer, which appeared more realistic than those merely taken with no modifications from the literature. Concerning metazoans, specific criteria have been applied depending on the life-cycle organization of each category of organism present in our case-study and also taking into account the time-scale which our case-study referred to.

As a general approach, consumption rates were derived from mass-specific ingestion rates (or daily carbon ration) recalculated from the literature. Consumption alone is not enough to characterize the trophic performances of heterotrophic organisms. In fact, a portion of the consumed biomass is not directed towards respiration and production and, being not assimilated by the animal, is eliminated. In this context, the assimilation efficiency, a variable usually estimated in feeding studies on planktonic animals, can be a good proxy for the non-assimilated fraction of consumed biomass, which is the fraction of undigested food emitted, e.g., as faeces and, eventually, consumed by other organisms.

\section{Derivation of primary production}

The production rate of the phytoplankton community as a whole was estimated in order to evaluate the differences in growth of photoautotrophic organisms living in the two different layers of the water column considered 
in our case-study. We analysed to this scope the only available data in our system, which were collected at LTER-MC on 1984. Thus, these data were only partially comparable to those used for defining the system's Carbon budget, which were collected during years 2000s.

Primary production data have been collected at the LTER-MC almost weekly during summer months of 19841988. The sampling was carried out, at $0.5,2,5,10,20$, $30,40,50,60 \mathrm{~m}$ of depth, as illustrated in Ribera d'Alcalà et al. (2004). The particulate primary production (PP) was estimated using a standard ${ }^{14} \mathrm{C}$ method. The integrated particulate primary production (PP) for the two layers (0-5 and $5-60 \mathrm{~m}$ in depth) considered in the present study was obtained by computing discrete values. Since the ${ }^{14} \mathrm{C}$ method estimated only PP, we inferred also the amount of exudates release (ER) to get the total primary production (TP), i.e. the sum of PP and ER. The latter quantity was derived using regressions pertaining all aquatic systems (Baines and Pace, 1991). Eventually, the production rate per unit of biomass was obtained by dividing TP by the total phytoplankton biomass (TB) estimated in D'Alelio et al. (2016). Production rates were estimated for each of the Green and Blue states. Production rates of phytoplankton FNs was set using as reference values both data collected as above and those obtained from the literature.

\section{Review of literature data}

Data collected from the literature and pertaining physiological and trophic properties of living nodes of the foodweb were analysed statistically. The correlation between body-size and each vital rate (i.e. production, consumption and assimilation rates) was investigated considering all living nodes, in order to identify size-related trends. Separate correlations were carried out for the distinct trophic conditions investigated (i.e., Green and Blue states). The large multivariate dataset including the ranges of all vital rates (production, consumption and assimilation rates and autotrophy/heterotrophy ratio) for all the studied conditions (i.e., Green and Blue states) was reduced and interpreted by means of Principal Component Analysis, with the aim of identifying possible groupings of living nodes based on trophic characteristics. Statistical analyses were carried out with the open-source software PAST (http://palaeo-electronica.org/2001_1/past/issue1_01.htm). All trophic links detected by our compilation of data from the literature were organized within a single dataset represented by a predator/prey matrix. This matrix was visualized using a network approach. A single food-web was displayed, which was representative of both Green and Blue states of the system. Indeed, the food-web was un-weighted (i.e., all links were quantitatively equivalent) and did not represent biomass fluxes, the latter option being out of the scope of the present work. This web aimed at aggregating links based on their directionality and displaying nodes hierarchically, based on their topological/trophic position. The network representing the coastal plankton food-web in the Gulf of Naples was built and analysed with the open-source software yEd 3.11.1 (yWorks GmbH, http://www.yworks. com). Network connectance analyses were carried out according to Beckerman et al. (2006).

\section{RESULTS AND DISCUSSION}

\section{Carbon budget of plankton in the Gulf of Naples during summer}

The gross repartitions of the overall amount of carbon (i.e., the sum of biomasses pertaining all nodes) in our system at Green and Blue states are presented in Fig. 2. Between the two trophic states, phytoplankton biomass underwent the largest variation in the surface water-layer (between 0 and $5 \mathrm{~m}$ in depth). Smaller changes were recorded in protozooplankton and heterotrophic bacteria pools at surface. Conversely, both mesozooplankton biomass and the whole particulate carbon pool in the deeper water-layer (5-60 $\mathrm{m}$ in depth) were almost unchanged at transitions between states. Overall, the mesozooplankton pool was lower than particulate carbon biomass. Mesozooplankton biomass was comparable to the collective unicellular biomass over the whole water column only during the Blue system state.

The plankton players in the studied food-web are represented by $63 \mathrm{FNs}$, including 17 for phytoplankton, 10 for mixotrophic-protozooplankton, 12 for heterotrophicprotozooplankton, 2 for heterotrophic bacteria, 5 for particulate detritus, 15 for mesozooplankton and 2 for dissolved organic carbon (DOM) (see nodes' list and description in Tab. 1). A wide spectrum of individual sizes characterized the plankton community (Fig. 3 A,D,G). Increasing of cell size was followed by a fairly regular increasing of the individual cell carbon, especially in unicellular organisms (compare Fig. 3A and B). Concerning metazoa, the picture was less regular, with e.g., calanoid copepod species featuring comparable sizes (i.e., prosomal length) but showing distinct individual biomasses (compare Fig. 3D and E).

Scaling-up to populations' biomasses, we estimated the differences for each FNs between the Green and Blue states (Fig. 3 C,F,H). Diatoms showed biomass changes of 2-3 orders of magnitude between the two states. Within the detritus pool, an increase of DOM was recorded at both surface and deeper layers at the Green state, as an effect of a larger amount of phytoplankton biomass, comparing to the Blue state. Moreover, the estimated salp faecal pellets also increased (of 1 order of magnitude) during the Green state. This fact stems from decreased assimilation efficiency for these animals into an environment with more abundant food particles. 


\section{Autotrophic unicellular organisms}

In this section, we present the ratio behind the derivation of ranges of production rates for autotrophic organisms (Tab. 2, Fig. 4). In compiling production rates for unicellular organisms, we assumed that they were equivalent to individual growth rates, i.e., cell doubling by mitotic division. However, while maximum production rates were considered equivalent to maximum growth rates found in the literature, the minimum production rates were derived as described in the Methods section and based on primary production data shown in the following subsection.

\section{Primary production}

In the Green state, minimum, maximum and median primary production rates accounted for $0.39,0.99,0.63$ and
$0.14,0.96,0.29 \mathrm{~d}^{-1}$ in the surface and deeper layers, respectively. In the Blue state, minimum, maximum and median primary production rates accounted for $0.22,0.85,0.52$ and $0.17,0.87,0.48 \mathrm{~d}^{-1}$ in the surface and deeper layers, respectively. Thus, in the deeper layer, the median value for primary production in the Blue state was about double than the corresponding value at the Green state (i.e., 0.48 vs 0.29 $\mathrm{d}^{-1}$ ). This fact is highly plausible, due to a higher light penetration towards deeper waters during the Blue state in absence of high phytoplankton biomass at the surface.

\section{Production rates}

Data in the literature, including both in situ and in vitro observations at conditions similar to those in the present case-study, were almost comparable with our direct ob-

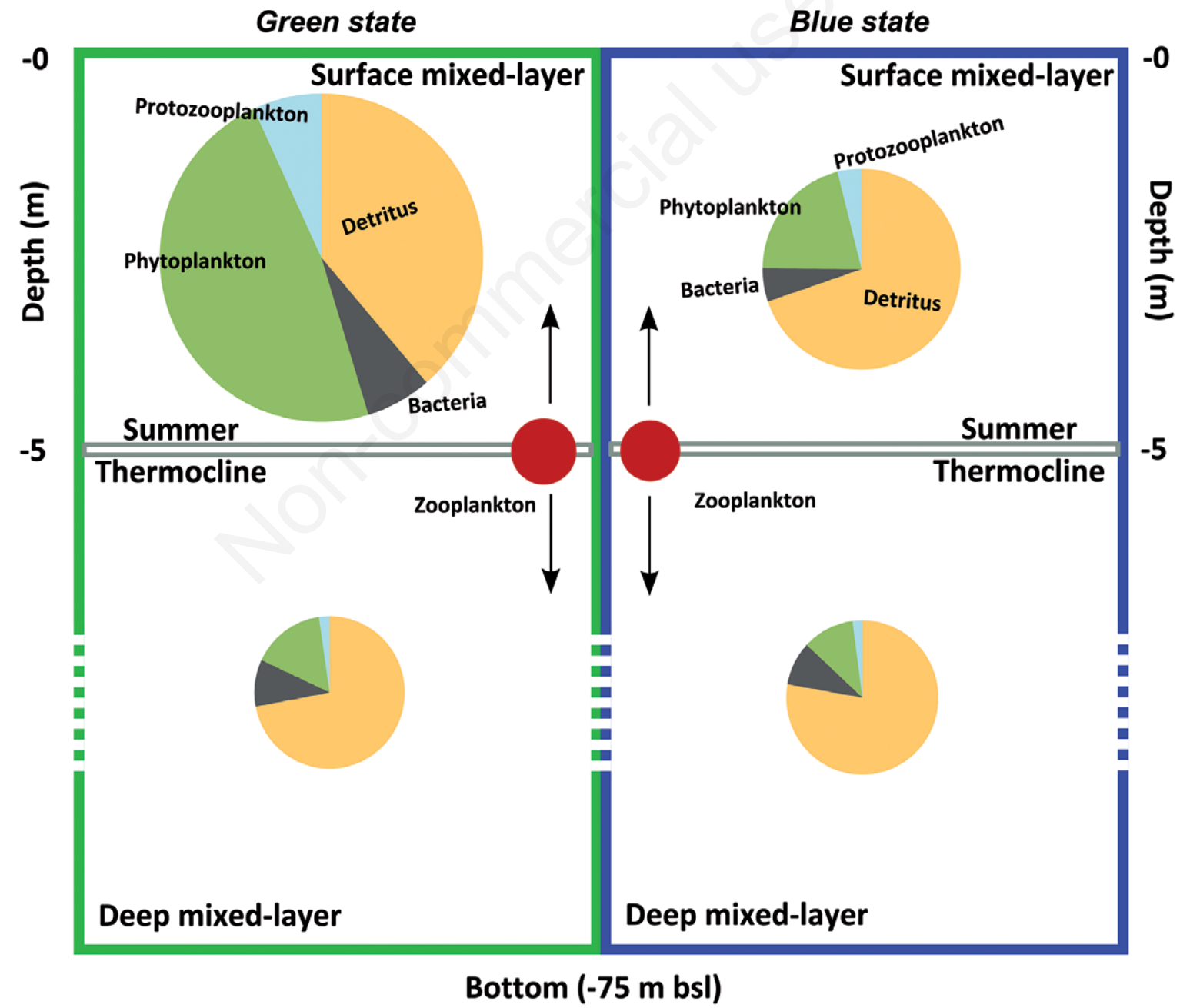

Fig. 2. Gross carbon-biomass budget during the Green-Blue swing. Panels represent the repartition of the total time-averaged (two months) amount of carbon among the main biomass compartments at LTER-MC, at the Green and Blue states of the system, respectively. Each panel is divided between surface and deeper water layers. 

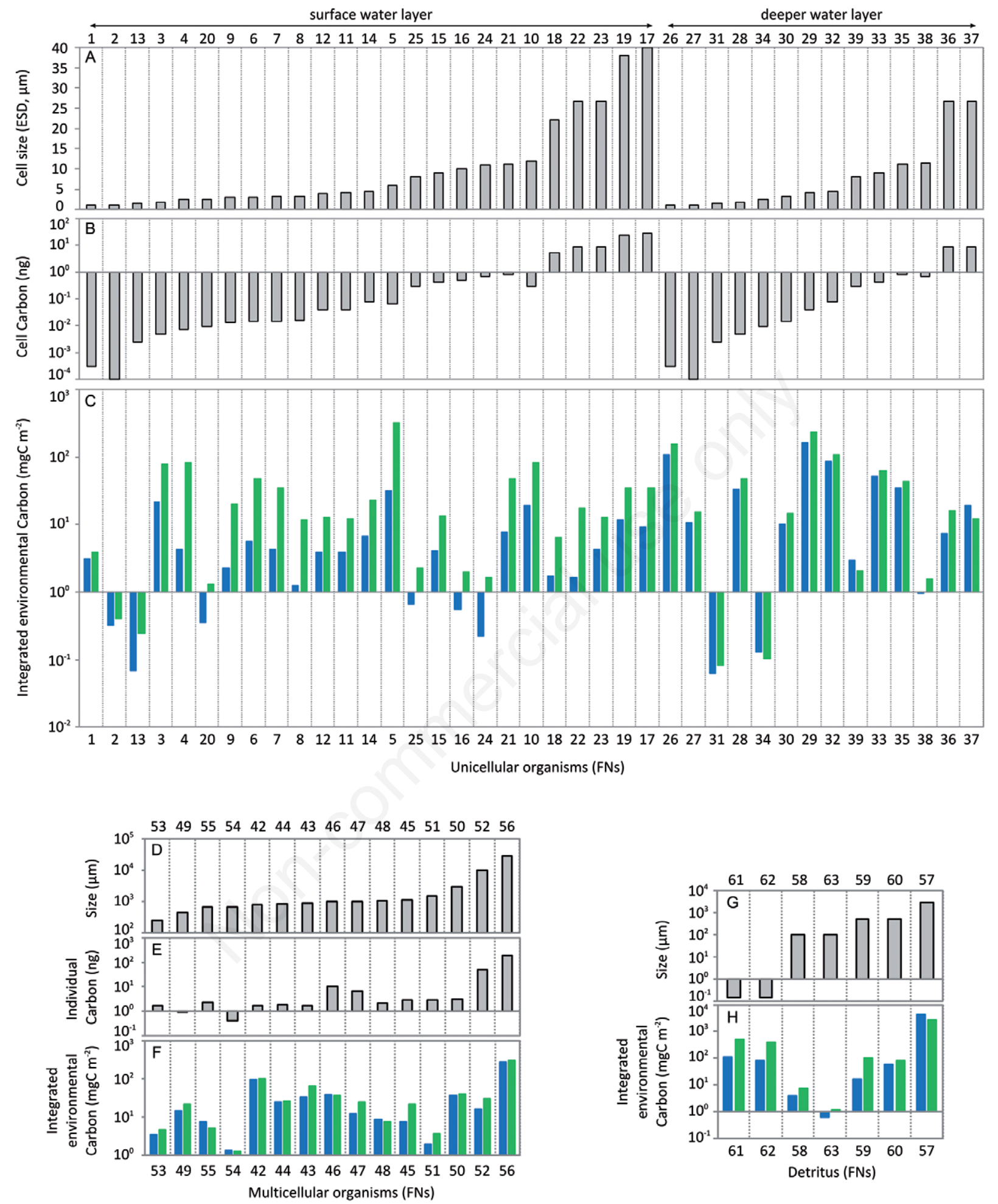

Fig. 3. Fine-scale carbon-biomass budget during the Green-Blue swing. In panels A-C, from top to bottom: cell-size (A) and individual cell-carbon (B) referring to unicellular functional nodes (FNs) of the food-web despite the specific trophic state; comparison of depth integrated environmental carbon-biomass (C) of unicellular FNs at the Green and Blue states (green and blue bars, respectively). In panels D-F: the individual size (D) and individual carbon (E) referring to metazoan FNs of the food-web despite the specific trophic state; comparison of depth integrated environmental carbon-biomass (F) of metazoan FNs at the Green and Blue states (green and blue bars, respectively). In panels $\mathrm{G}$ and $\mathrm{H}$ : size of detritus nodes $(\mathrm{G})$ and the depth integrated environmental carbon-biomass (H) of detritus FNs at the Green and Blue states (green and blue bars, respectively). Functional nodes are listed in Tab. 1. 
Tab. 1. Functional nodes of the web.

\begin{tabular}{|c|c|c|}
\hline Functional nodes (FN) & Small description & Trophic status \\
\hline 1 Cyanobacteria (s) & Mainly Synechococcus & A \\
\hline 2 Prochlorophytes (s) & Mainly Prochlorococcus & A \\
\hline 3 Phyto-nanoflagellates (s) & Several genera and N.I.T. & A \\
\hline 4 Chaetoceros spp. (s) & Different species in this diatom genus & A \\
\hline $5 \quad$ Leptocylindrus spp. (s) & Different species in this diatom genus & A \\
\hline 6 Skeletonema spp. (s) & Different species in this diatom genus & A \\
\hline 7 Small diatoms (s) & Several genera and N.I.T. & A \\
\hline 8 Pennate diatoms (s) & Thalassionema spp., N.I.T. (cell size $>10 \mu \mathrm{m}$ ) & A \\
\hline $9 \quad$ Pseudo-nitzschia spp. (s) & Different species in this diatom genus & A \\
\hline 10 Centric diatoms (s) & Several genera & A \\
\hline 11 Coccolithophores (s) & Mainly N.I.T. plus Emiliania huxleyi and several genera & A \\
\hline 12 Phyto-microflagellates (s) & Several genera and N.I.T. & A \\
\hline 13 Mixotrophic nanoflagellates (s) & Mainly Ollicola vangorii & M \\
\hline 14 Small dinoflagellates (s) & Several genera and N.I.T. & M \\
\hline 15 Medium dinoflagellates (s) & Several genera and N.I.T. & M \\
\hline 16 Mesodinium rubrum (a) & (Syn. Myrionecta rubra) ciliate & M \\
\hline 17 Tontonia spp. (s) & Oligotrichous ciliate genus & M \\
\hline $18 \quad$ Laboea spp. (s) & Oligotrichous ciliate genus & M \\
\hline 19 Strombidium spp. (s) & Oligotrichous ciliate genus & M \\
\hline 20 HNF (s) & Heterotrophic nanoflagellates & $\mathrm{H}$ \\
\hline 21 Heterotrophic dinoflagellates (s) & Several genera & $\mathrm{H}$ \\
\hline 22 Prostomatids (s) & Ciliates & $\mathrm{H}$ \\
\hline 23 Strobilidium spp. (s) & Single ciliate genus & $\mathrm{H}$ \\
\hline 24 Tintinnids (s) & Several genera & $\mathrm{H}$ \\
\hline $25 \quad$ Nanociliates (s) & Ciliates & $\mathrm{H}$ \\
\hline 26 Cyanobacteria $(\mathrm{d})$ & Mainly Synechococcus & A \\
\hline 27 Prochlorophytes $(\mathrm{d})$ & Mainly Prochlorococcus & A \\
\hline 28 Phyto-nanoflagellates (d) & Several genera and N.I.T. & A \\
\hline 29 Coccolithophorids (d) & Mainly Emiliania huxleyi & A \\
\hline 30 Diatoms $(\mathrm{d})$ & Several genera & A \\
\hline 31 Mixotrophic nanoflagellates (d) & Mainly Ollicola vangorii & M \\
\hline 32 Small dinoflagellates $(\mathrm{d})$ & Several genera and N.I.T. & M \\
\hline 33 Medium dinoflagellates (d) & Several genera and N.I.T. & M \\
\hline $34 \quad \mathrm{HNF}(\mathrm{d})$ & Heterotrophic nanoflagellates & $\mathrm{H}$ \\
\hline 35 Hetero- dinoflagellates (d) & Several genera & $\mathrm{H}$ \\
\hline 36 Prostomatids (d) & Ciliates & $\mathrm{H}$ \\
\hline 37 Strobilidium spp. (d) & Single ciliate genus & $\mathrm{H}$ \\
\hline 38 Tintinnids $(\mathrm{d})$ & Several genera & $\mathrm{H}$ \\
\hline 39 Nanociliates $(d)$ & Ciliates & $\mathrm{H}$ \\
\hline 40 Heterotrophic bacteria (s) & - & $\mathrm{H}$ \\
\hline 41 Heterotrophic bacteria (d) & - & $\mathrm{H}$ \\
\hline 42 Penilia avirostris (a) & Cladoceran & $\mathrm{H}$ \\
\hline 43 Cladocerans (a) & Evadne and Pseudevadne spp. & $\mathrm{H}$ \\
\hline 44 Paracalanus parvus (a) & Calanoid copepod (adults) & $\mathrm{H}$ \\
\hline $45 \quad$ Acartia clausii (a) & Calanoid copepod (adults) & $\mathrm{H}$ \\
\hline 46 Temora stylifera (a) & Calanoid copepod (adults) & $\mathrm{H}$ \\
\hline 47 Centropages typicus (a) & Calanoid copepod (adults) & $\mathrm{H}$ \\
\hline 48 Other calanoids (a) & Genera (adults) & $\mathrm{H}$ \\
\hline 49 Juvenile calanoids (a) & Mainly juveniles stages of Clausocalanus spp., Paracalanus parvus & $\mathrm{H}$ \\
\hline 50 Appendicularia (a) & Different genera & $\mathrm{H}$ \\
\hline 51 Doliolids (a) & Mainly Doliolum nationalis & $\mathrm{H}$ \\
\hline 52 Salps (a) & Different genera & $\mathrm{H}$ \\
\hline 53 Meroplankton (a) & Larval stages of Anellida Polychaeta, Crustacea Maxillopoda, Echinodermata, Mollusca & $\mathrm{H}$ \\
\hline 54 Oithona spp. (a) & $\begin{array}{l}\text { Different life stages of } O \text {. atlantica, } O \text {. decipiens, } O \text {. longispina, } O . \text { nana, } O \text {. setigera, } \\
\text { O. similis }\end{array}$ & $\mathrm{H}$ \\
\hline
\end{tabular}


Tab. 1. Continued from previous page.

\begin{tabular}{lllc} 
Functional nodes (FN) & Small description & Trophic status \\
55 & Detritivora (a) & $\begin{array}{l}\text { Corycaeus spp., Farranula rostrata and Oncaeidae (Copepoda Cyclopoida) plus } \\
\text { Euterpina acutifrons (Copepoda Harpacticoida) }\end{array}$ & H \\
56 & Carnivora (a) & $\begin{array}{l}\text { N.I.T. of Chaetognata, Mollusca Pteropoda, Cnidaria Siphonophora plus Candacia spp. } \\
\text { and Pleuromamma } \text { spp. (Copepoda Calanoida) }\end{array}$ & H \\
\hline 57 & Appendicularia houses (a) & - & $\mathrm{D}$ \\
58 & Small faecal pellets (a) & Faecal pellets of small animals & $\mathrm{D}$ \\
\hline 59 & Salp F.P. (a) & Faecal pellets of salps & $\mathrm{D}$ \\
60 & Carnivora F.P. (a) & Faecal pellets of carnivores & $\mathrm{D}$ \\
\hline 61 & DOC (s) & Dissolved organic carbon & $\mathrm{D}$ \\
62 & DOC (d) & Dissolved organic carbon & $\mathrm{D}$ \\
\hline 63 & Generic particulate detritus (a) & Amorphous particulate detritus & \\
\hline
\end{tabular}

(s) In the surface water-layer; (d) in the deeper water-layer; (a) living all over the water column; A, autotrophic; H, heterotrophic; M, mixotrophic; D, detritus; N.I.T., non identified taxa.

servations based on $\mathrm{C}^{14}$ method. Moreover, the maximum values gained from primary production data were below the maximum values gained from growth rates retrieved from the literature. Relatively low values were recorded for prokaryotes - i.e., $1.2 \mathrm{~d}^{-1}$ for Synechococcus (FN 1) during summer months (Sosik et al., 2003), and 0.69-0.85 $\mathrm{d}^{-1}$ for prochlorophytes (FN 2) (Liu et al., 1997); on the other hand, an exhaustive and recent review reported values up to $2.5 \mathrm{~d}^{-1}$ for unicellular planktonic photo-eukaryotes (Edwards et al., 2012). After re-modulating growth rates based on primary production data shown in the previous paragraph, both maximum and minimum production rates of phototrophs (e.g., coccolithophores and diatoms, FN 29-30) in the deeper water-layer where higher in the Blue than in the Green state. The analyses of primary production in situ informed us that the physiological state of phytoplankton species was comparable at Green and Blue states. Thus, in the surface and more productive water-layer, the same range of variability of production rates of phytoplankton species was assumed to occur in Green and Blue states.

\section{Mixo- and heterotrophic unicellular organisms (protozooplankton)}

In the following paragraphs, literature references and specific rationales for the calculation of production, consumption and assimilation rates of mixotrophic and heterotrophic unicellular organisms and presented in Tab. 3 and Fig. 4 are provided. Diet of unicellular consumers is discussed in the dedicated paragraph and presented in Fig. 5.

\section{Production rates}

Unlike phototrophic protists, the physiology of mixotrophic ciliates is largely unknown since these organisms are not easily cultivated in the laboratory or studied in the field. Mixotrophic ciliates in our system of study were mainly oligotrichous ciliates of the genera Tontonia, Laboea and Strombidium (FN 17-19). The maximum production rates indicated herein for these organisms $\left(\sim 1.5 \mathrm{~d}^{-1}\right)$ were obtained from multiple regression between growth, temperature and cell volume (Pérez et al., 1997). We considered a temperature of $25^{\circ} \mathrm{C}$ (average value for the surface layer in the GoN during summer). The obtained values were in line with those reported in specific studies (e.g., Schoener and McManus, 2012). A specific case was represented by Mesodinium rubrum (syn.

Tab. 2. Vital rates of phytoplankton.

\begin{tabular}{lllll} 
FN & \multicolumn{2}{c}{ Blue state } & \multicolumn{2}{c}{ Green state } \\
& \multicolumn{2}{c}{ Production min-max } & $\mathbf{d}^{-1}$ \\
\hline 1 & 0.31 & 1.20 & 0.47 & 1.20 \\
\hline 2 & 0.22 & 0.85 & 0.33 & 0.85 \\
\hline 3 & 0.49 & 1.90 & 0.75 & 1.90 \\
4 & 0.53 & 2.04 & 0.80 & 2.04 \\
\hline 5 & 0.27 & 1.06 & 0.42 & 1.06 \\
\hline 6 & 0.43 & 1.67 & 0.66 & 1.67 \\
\hline 7 & 0.43 & 1.65 & 0.65 & 1.65 \\
\hline 8 & 0.42 & 1.62 & 0.64 & 1.62 \\
\hline 9 & 0.45 & 1.74 & 0.69 & 1.74 \\
10 & 0.16 & 0.61 & 0.24 & 0.61 \\
\hline 11 & 0.44 & 1.70 & 0.67 & 1.70 \\
\hline 12 & 0.39 & 1.50 & 0.59 & 1.50 \\
\hline 26 & 0.29 & 1.11 & 0.22 & 0.55 \\
\hline 27 & 0.20 & 0.78 & 0.15 & 0.39 \\
\hline 28 & 0.45 & 1.75 & 0.34 & 0.87 \\
\hline 29 & 0.41 & 1.57 & 0.31 & 0.78 \\
\hline 30 & 0.40 & 1.53 & 0.30 & 0.76 \\
\hline & & & &
\end{tabular}

$\mathrm{FN}$, functional node. 


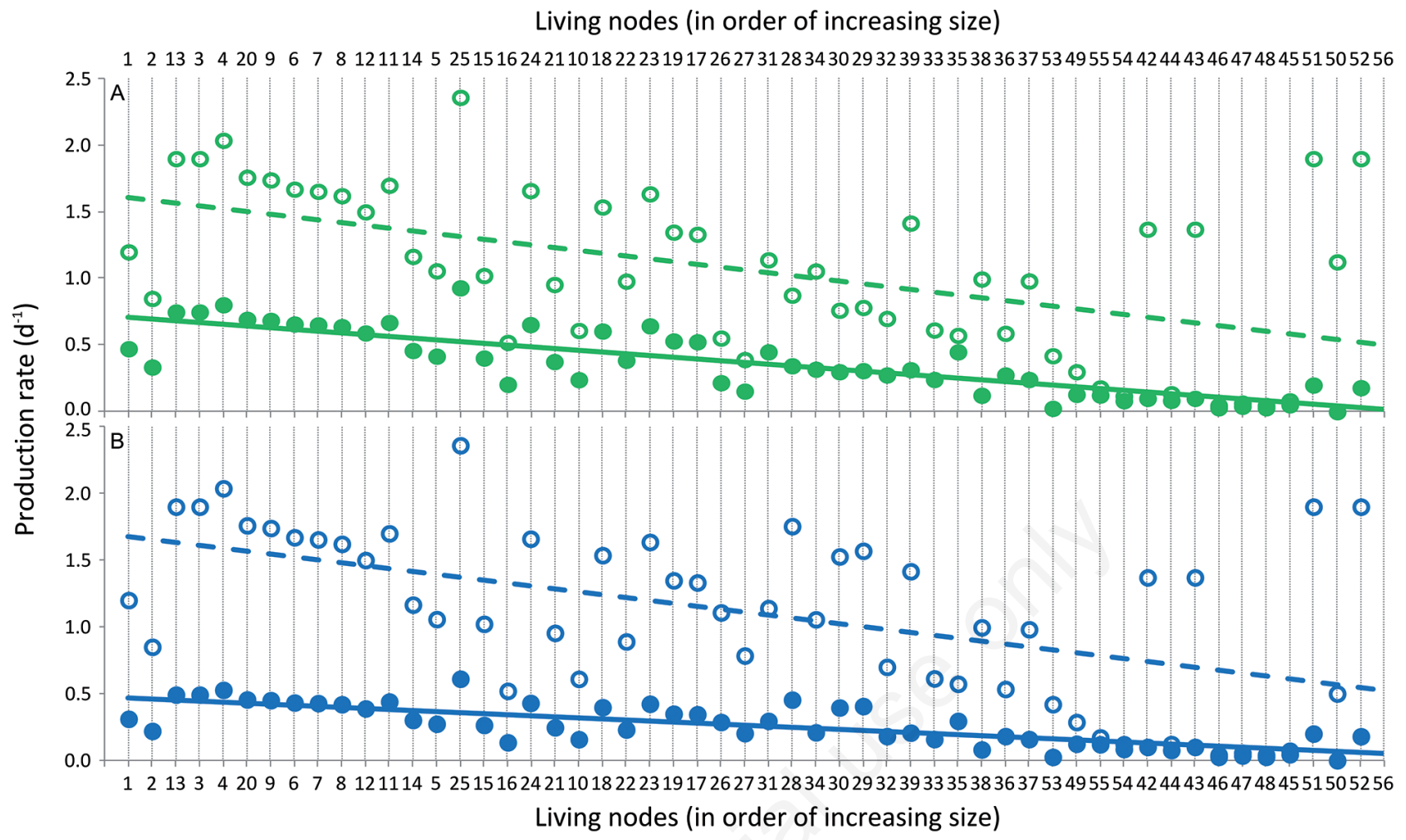

Consumer nodes (in order of increasing size)

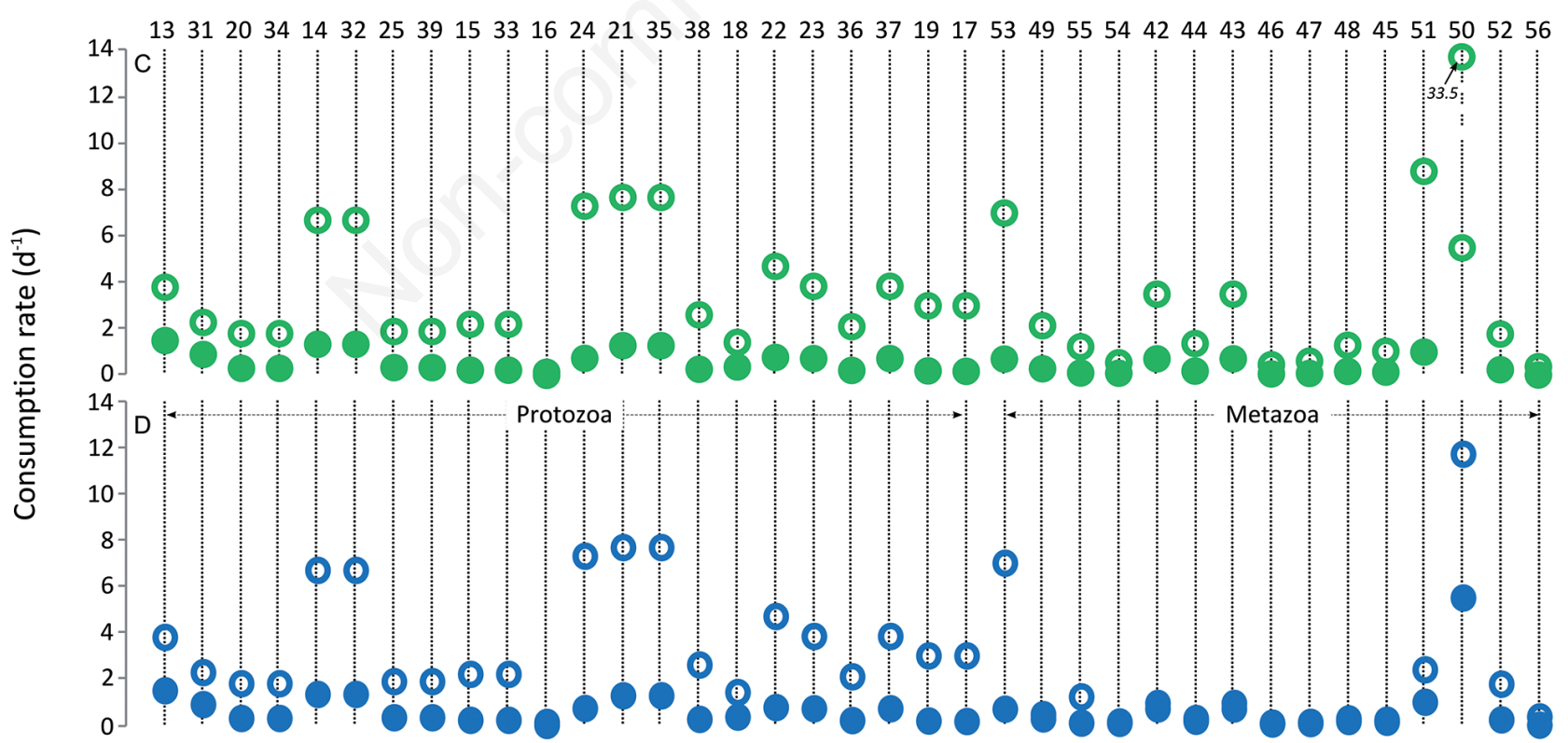

$1331203414322539153316242135381822 \quad 233637191753495554 \quad 4244 \quad 434647484551505256$

Consumer nodes (in order of increasing size)

Fig. 4. Vital rates of FNs at Green and Blue states. In panels A and B, production rates for FNs during Green and Blue states, respectively. In panels $\mathrm{C}-\mathrm{D}$, consumption rates for FNs during Green and Blue states, respectively. Empty and full circles indicate maximum and minimum values, respectively. FNs are listed in Tab. 1. 
Myrionecta rubra) (FN 16). This species blooms mainly at low salinity (about 10) in coastal transition systems (Johnson et al., 2013). Although salinity in our system of study is usually higher (around 37), we considered a maximum production rate of $0.52 \mathrm{~d}^{-1}$ for M. rubrum based on estimation made in culture at 31 (Yih et al., 2004), i.e., the only data available. Finally, due to scanty background knowledge, we assigned to mixotrophic nanoflagellates (FN 13) the same value as for phyto-nanoflagellates (FN 3) (approaching $2 \mathrm{~d}^{-1}$ ), which was derived from (Edwards et al., 2012). Concerning mixotrophic dinoflagellates (FN 14-15), the maximum production rate $\left(\sim 1 \mathrm{~d}^{-1}\right)$ was obtained with the regression relating growth rate to metabolic state and cell size reported by (Jeong et al., 2010).

Scanty information was available also for obligate heterotrophic protists. The maximum production rate for Heterotrophic nanoflagellates (FN 20) $\left(\sim 1.5 \mathrm{~d}^{-1}\right)$ was based on Weisse (1997), i.e., the only one study available. The maximum value for heterotrophic dinoflagellates was obtained with the same regression used for mixotrophic ones (Jeong et al., 2010). Growth rate data for prostomatids (FN 22, cell size $>20 \mu \mathrm{m}$ ) were also scarce in the literature. To the best of our knowledge, the physiological performance was studied only for the species Tiarina fusus and values of maximum production rate at $19^{\circ} \mathrm{C}$ were reported to range $0.1-0.47 \mathrm{~d}^{-1}$, depending on the prey provided as food (Jeong et al., 2002). By applying a $\mathrm{Q}_{10}$ of 2.8 - an average value for ciliates according to (Hansen and Bjørnsen, 1997) - the maximum production rate of prostomatids at $25^{\circ} \mathrm{C}$ resulted $0.98 \mathrm{~d}^{-}$ ${ }^{1}$. The maximum value for the heterotrophic oligotrichous ciliates of the genus Strobilidium spp. (FN 23) $\left(\sim 1.5 \mathrm{~d}^{-1}\right)$ was derived through the equation reported by Pérez et al. (1997), considering the specific biovolume and a temperature of $25^{\circ} \mathrm{C}$. A wide literature was available for growth rates of tintinnids (FN 24) estimated from in situ observations carried out during summer (Verity, 1986). Finally, nanociliates in our case-study (FN 25, cell size $<20 \mu \mathrm{m}$ ) included both prostomatids and other ciliates. Information about their growth performances were scarce and we

Tab. 3. Vital rates of protozooplankton.

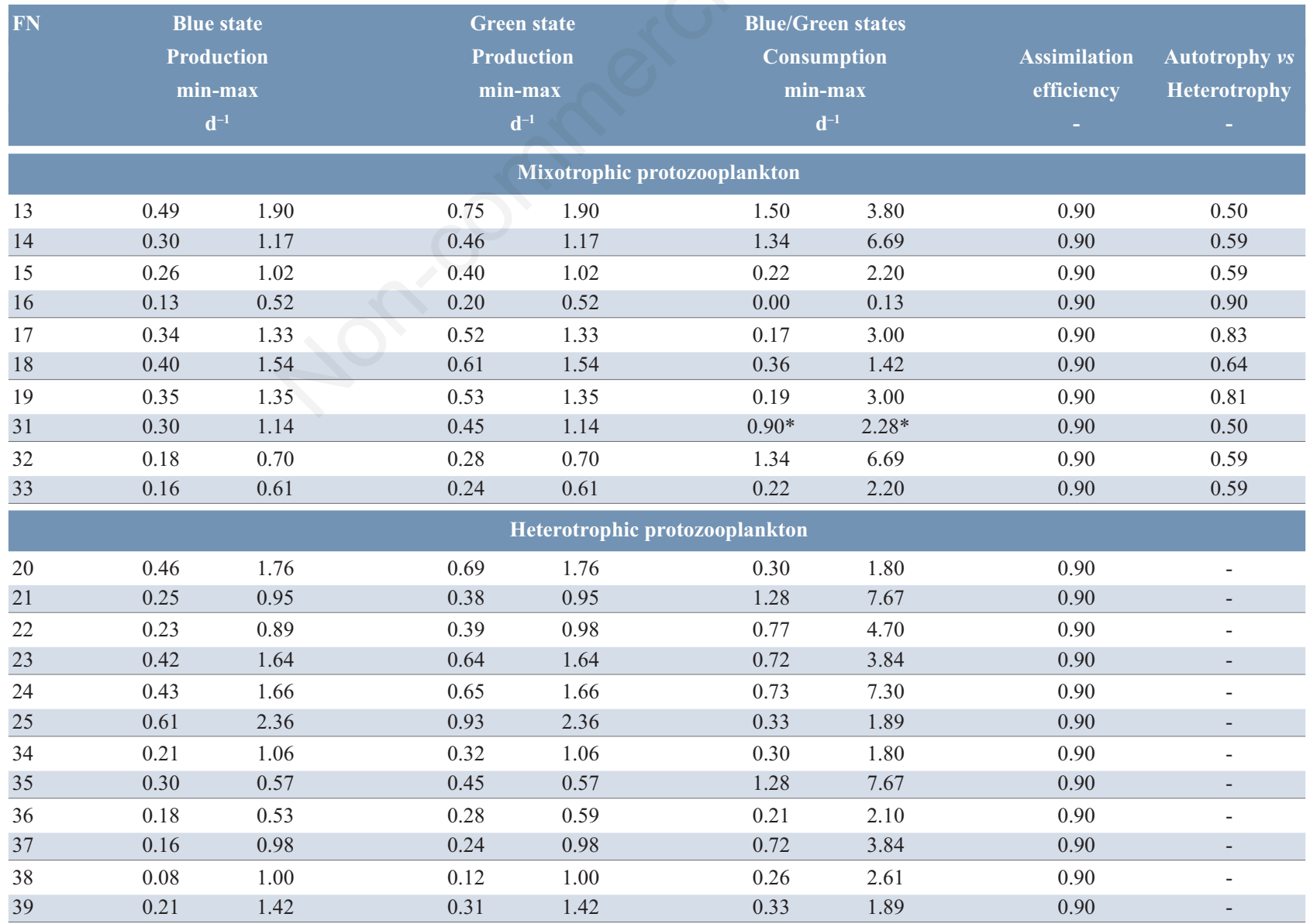

FN, functional node. 
used data from Franzé and Modigh (2013), who reported max growth rates up to $2.36 \mathrm{~d}^{-1}$ for a nanociliate assemblage under laboratory conditions and relaxed intra-guild predation.

\section{Consumption and assimilation rates}

Autotrophy and heterotrophy alternate in the metabolism of mixotrophic organisms. A gross estimation of the extent of alternation between these life-strategies is given by the ratio of daily production associated to autotrophy, which is presented in Tab. 3. Scanty information was available about specific ingestion rates of mixotrophic flagellates, which were represented mainly by Ollicola vangoorii (FN 13 and FN 31, in surface and deeper layers, respectively). We assumed that consumption rates in these organisms were never lower than twice the production rates in the same organisms, a value largely enough to guarantee their metabolisms. Since no information was available in the literature regarding growth and metabolism in Ollicola vangorii, we assumed that $50 \%$ of the biomass production in this organism was carried out via photo-autotrophy.

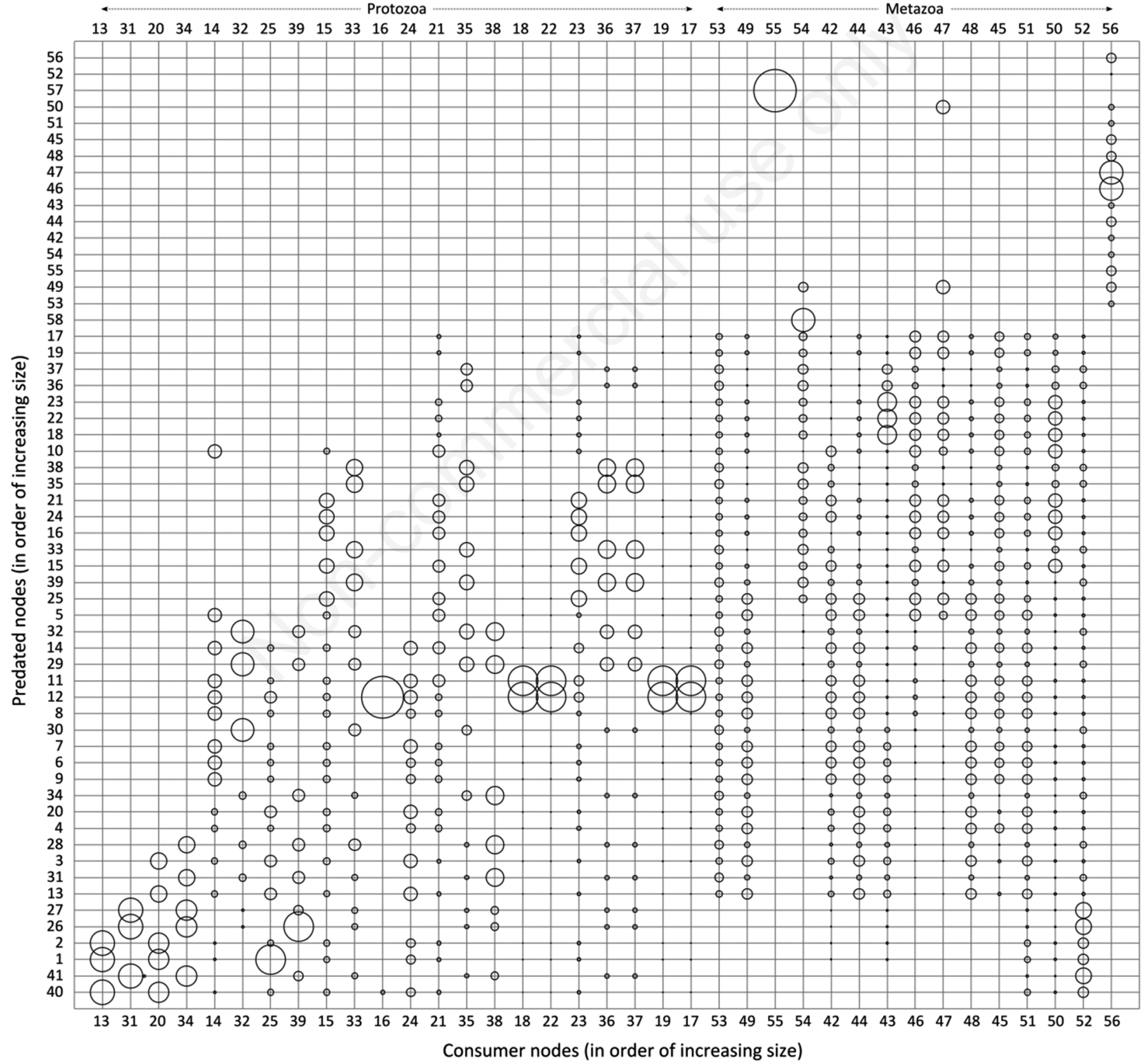

Fig. 5. Diet-matrix of FNs. Each data-point represents a trophic link; columns and rows represent consumers and preys, respectively. The dimension of a circle is proportional to the weight of the link in the diet of the consumer, which is represented by the spectrum of circles within the column. FNs are listed in Tab. 1. 
The obligate mixotroph M. rubrum (syn. M. rubra) (FN 16) is reported to ingest a maximum amount of carbon corresponding to $13.1 \%$ of its body-mass, on a daily basis (recalculated data from Yih et al., 2004). This value would be in line with the ratio of ingested versus autotrophically-produced carbon amounts (i.e., 0.10 vs 0.90, respectively). Such a high value stems from the fact that the captured plastids can divide within this ciliate and can be transmitted throughout a clonal line, unlike for the other mixotrophic ciliates which need to acquire new plastids after some cellular divisions (Stoecker et al., 2009 and references therein). The minimum consumption rate for $M$. rubrum was assumed close to zero, after considering the high photosynthetic performances of this species.

The oligotrichous ciliates Laboea spp., Tontonia spp. and Strombidium spp. (FN 17-19) engulf microalgae and retain their plastids but are not able to maintain plastidialdivision (Stoecker et al., 2009 and references therein). Aplastidic cells were rarely reported in these genera, which relied on photosynthesis to cover a large part of the respiration demand and showed growth limitation in absence of plastids; on average, the overall contribution of photosynthesis to production was around 55\% (Stoecker et al., 2009 and references therein). A meta-analysis based on published data (Dolan and Perez, 2000) estimated that, close to light-saturation $(200 \mu \mathrm{E}$, i.e., an amount of light comparable with that in the surface layer of the GoN during summer), the carbon-fixation rate in plastidic oligotrichous ciliates had an average value of $5 \mathrm{fg} \mathrm{C}$ per $\mu \mathrm{m}^{-3}$ of ciliate-biovolume per hour, and this rate was independent from the size of the ciliate. Based on these assessments, we calculated that the fraction of biomass obtained via photosynthesis at saturating light was $0.81,0.64$ and 0.83 in Strombidium, Laboea and Tontonia (FNs 17-19), respectively, considering a summer day-length of $14 \mathrm{~h}$.

For what concerns the genus Strombidium spp. (FN $19)$, the ingestion rate of the species $S$. rassoulzadeganii was within $3 \mathrm{~d}^{-1}$ (i.e., $300 \%$ the body-mass) at concentrations of food comparable to those found in our system in the surface layer $\left(<0.5 \mathrm{~g} \mathrm{C} \mathrm{m}^{-3}\right)$ (Schoener and McManus, 2012). Considering that a Strombidium cell should cover up to $81 \%$ of its metabolic needs via photosynthesis, the minimum consumption rate would account for about 0.19 $\mathrm{d}^{-1}$. Laboea strobila (FN 18) can ingest up to $5.9 \%$ of its biomass per hour, giving a maximum consumption rate of $1.42 \mathrm{~d}^{-1}$ (Stoecker et al., 2009), though assuming that ingestion rates were equivalent during day and night (but this is not always valid, see, e.g., Jakobsen and Strom, 2004). Following the same rationale adopted for the other oligotrichous ciliates, minimum consumption rate for $L$. strobila should be about $0.36 \mathrm{~d}^{-1}$. Since no information was found for the genus Tontonia (FN 17), we assumed that the consumption rate of this ciliate should be similar to that of Strombidium, based on similarities of cellular biomass and metabolism (i.e., ratio between autotrophy and heterotrophy). The minimum consumption rate for this protist was assumed as $\sim 0.17 \mathrm{~d}^{-1}$, according with the criteria adopted for other mixotrophic oligotrich ciliates.

Tab. 4. Vital rates of mesozooplankton.

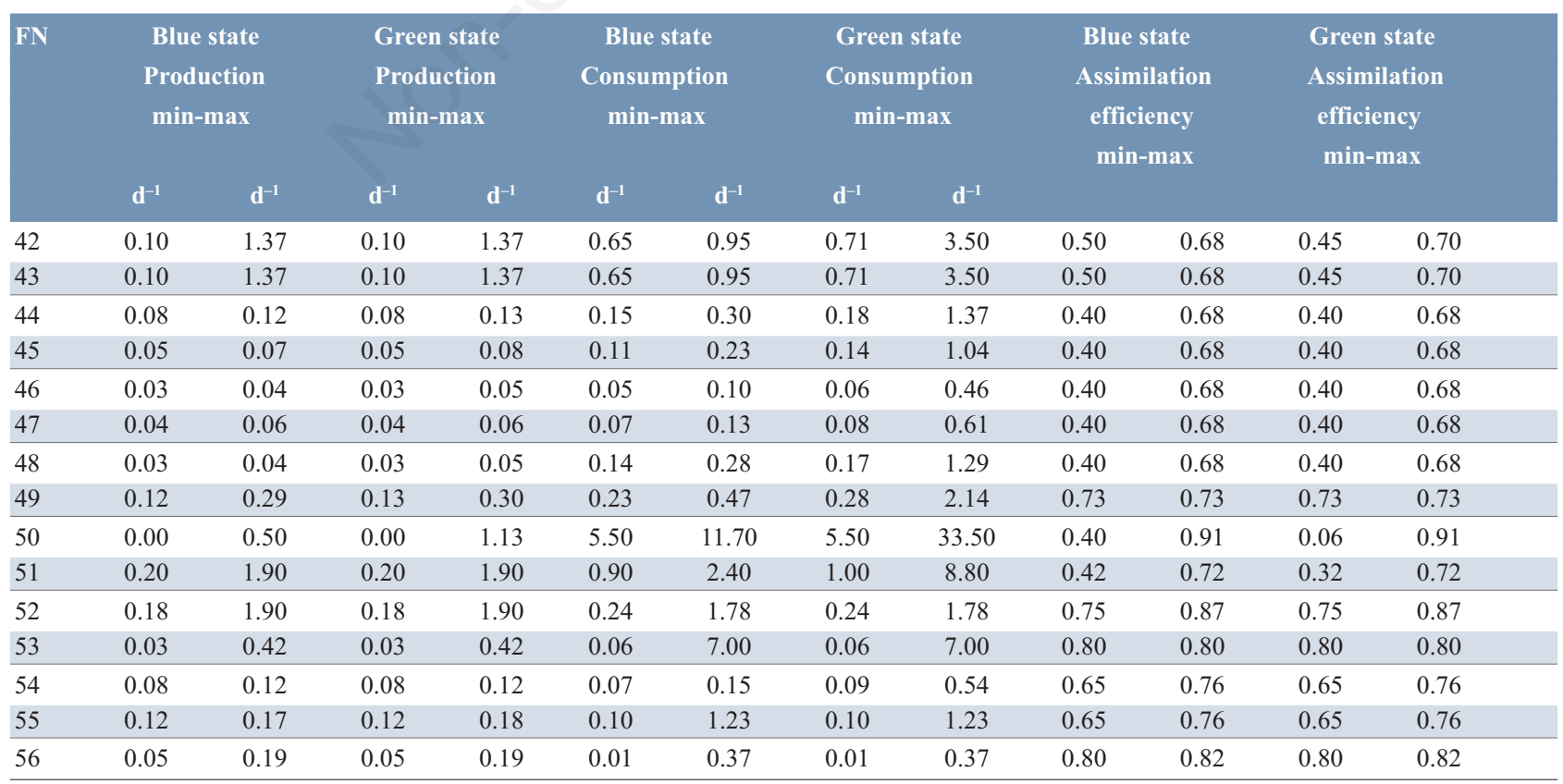

FN, functional node. 
Small and medium mixotrophic dinoflagellates (FN 14-15) bear proper plastids, which are transmitted to their progeny after cell-division. Autotrophy could account for $59 \%$ of their growth rate and, consequently, of their metabolism (recalculations from data in Fig. 4 and Tabs. 3 and 4 in Jeong et al., 2010). The consumption rate for dinoflagellates in our study system was derived based on meta-analyses of published experimental data and relating regressions (Jeong et al., 2010 and references therein). Smaller- and medium-sized mixotrophic dinoflagellates (in our study system, showing an ESD of 9 and $18 \mu \mathrm{m}$, respectively, and included in FN 14-15 for the surface and FN 32-33 for the deeper layer) showed a maximum consumption rate of 6.69 and $2.205 \mathrm{~d}^{-1}$, respectively. Obligate heterotrophic dinoflagellates (in our study system, showing an ESD of about $22 \mu \mathrm{m}$ and included in FN 21 and 35 for surface and deeper layer, respectively) showed a maximum consumption rate of $7.674 \mathrm{~d}^{-1}$. For what concerns the minimum consumption rate of a dinoflagellate node, in absence of specific values in the literature, these were set as double the minimum production rate of the same node - i.e., 1.338 and $0.22 \mathrm{~d}^{-1}$ for smaller and larger mixotrophic dinoflagellates and $1.279 \mathrm{~d}^{-1}$ for heterotrophic dinoflagellates. Since it was not possible to disentangle the effect of temperature on the ingestion rate from the information available in the literature, the consumption rates' ranges described above are considered as representing dinoflagellates present in both water layers considered in our study system.

The feeding performances of prostomatids (FN 22 and 36) have been poorly studied. The ingestion rates of Tiarina fusus at $17^{\circ} \mathrm{C}$ and at food concentrations comparable to those reached in the GoN during summer ranged 0.21-2.1 $\mathrm{d}^{-1}$ (Jeong et al., 2002). The latter values were taken as the minimum-maximum consumption range for the deep prostomatids ( $\mathrm{FN} \mathrm{36}$ ) in our case study, living at $\mathrm{T}=15^{\circ} \mathrm{C}$. Considering a $\mathrm{Q}_{10}$ of 2.8 specific for ciliates (Hansen and Bjørnsen, 1997), and references therein), the consumption rate for prostomatids in the surface layer (FN 22) should range 0.77-4.7 $\mathrm{d}^{-1}$. Concerning Strobilidium (FN 23 and 37, in surface and deeper layers, respectively), weight-specific ingestion rates were in the range $0.03-0.16 \mathrm{~h}^{-1}$ in Strobilidium cf. spiralis (Verity, 1991), with the higher value gained at a saturating food concentration of $250 \mathrm{mg} \mathrm{C} \mathrm{m}^{-3}$, a value in the range of our system of study during summer. Since consumption rates of Strobilidium during the day and the night were comparable according to (Jakobsen and Strom, 2004), daily consumption rates for Strobilidium in our casestudy (FN 23) should range $0.72-3.84 \mathrm{~d}^{-1}$. This range referred to a single temperature $\left(20^{\circ} \mathrm{C}\right.$, intermediate between our environmental extremes) but we assumed it as representative for both surface and deeper layers populations (FNs 23 and 37).

The consumption rates of tintinnids at $25^{\circ} \mathrm{C}$ ranged
0.73-7.3 $\mathrm{d}^{-1}$ (data for Tintinnopsis acuminata, recalculated from Verity (1985), assuming that ingestion rates during day and night were comparable). This range was herein considered for tintinnids in the surface layer (FN 24). When applying a $\mathrm{Q}_{10}$ of 2.8 (Hansen and Bjørnsen, 1997), the consumption rate for tintinnids in the deeper layer (FN 38 ) should range $0.26-2.61 \mathrm{~d}^{-1}$. Nanociliates (FNs 25 and 39 , in surface and deeper layers, respectively) included specimens with a cell-size $<20 \mu \mathrm{m}$ (average $\mathrm{ESD}=16$ $\mu \mathrm{m})$. A cell of the marine genus Uronema (ESD about 12 $\mu \mathrm{m}$, comparable to those in our case-study) can ingest up to 31 Synechococcus cells hour ${ }^{-1}$ at light conditions (Christaki et al., 1999). Considering that the ingestion rate of nanociliates is $120 \%$ higher in the dark (data for Balanus comatum, Jakobsen and Strom, 2004), the whole amount of cells ingested per day by one nanociliate should be 68.2 , giving a specific rate of ingestion of $1.89 \mathrm{~d}^{-1}$. Since the experimental data considered were gained at $20^{\circ} \mathrm{C}$ (intermediate between 15 and $25^{\circ} \mathrm{C}$ ) (Christaki et al., 1999), and since a $\mathrm{Q}_{10}$ specific for nanociliates was not available in the literature, maximum consumption rate for both the surface and deeper populations (FN 25 and 39) was considered as $1.89 \mathrm{~d}^{-1}$. This value is relatively high, enabling these organisms to sustain their metabolism at the highest rate of production. Moreover, since the functional response (i.e., the consumption rate in function of food concentration) for nanociliates was unknown, the minimum consumption rate at both surface and deeper layers was assumed to be proportional to the maximum consumption rate and the ratio between minimum and maximum consumption rates of other heterotrophic ciliates (i.e. prostomatids and Strobilidium), i.e., $0.33 \mathrm{~d}^{-1}$.

Finally, according with the literature, mixo- and heterotrophic unicellular organisms were assumed to be highly efficient in energetic terms and to have an assimilation efficiency $\sim 1$ (Stoecker et al., 2009 and reference therein).

\section{Diet}

This paragraph describe in detail the derivation of values included in Fig 5. The trophic links presented herein are considered valid for both Green and Blue states.

Dinoflagellates, including both mixotrophic and heterotrophic taxa, were reported to eat a wide array of preys (Sailley and Buitenhuis, 2014). According to laboratory observations (Jeong et al., 2010), mixotrophic and heterotrophic dinoflagellates were more actively feeding when predator:prey size ratios ranged 0.8-5.8 and 0.4-5.3, respectively; moreover, the higher ingestion rates were observed when predator to prey size ranged 0.8-1.4 and 0.9-2.6 for mixotrophic and heterotrophic dinoflagellates, respectively. According to size-selectivity, small mixotrophic dinoflagellates in our case-study (average equivalent sphere diameter, i.e., $\mathrm{ESD}=4.5 \mu \mathrm{m}, \mathrm{FN} 14$ and 32) would predate preferentially bacteria, prochlorophytes 
(ESD $<1 \mu \mathrm{m}$ ), other small-sized dinoflagellates (ESD within $10 \mu \mathrm{m}$; cannibalistic feeding) and diatoms. In turn, larger mixotrophic dinoflagellates (avg. $\mathrm{ESD}=9 \mu \mathrm{m}, \mathrm{FN}$ 15 and 33) would eat all other unicellular organisms, except for large ciliates (ESD $>40 \mu \mathrm{m}$ ). Obligate heterotrophic dinoflagellates (avg. ESD $11.1 \mu \mathrm{m}, \mathrm{FN} 21$ and 35 ) would eat over an even wider prey-range.

Heterotrophic nanoflagellates (HNF, FN 20 and 34) and nanociliates (FN 25 and 39) were among the smallest consumers in the studied food-web. Bacterivory was reported as the dominant feeding behaviour of HNF (Novarino et al., 2002). HNF were reported to assume, at daily basis, from 12 to $60 \%$ of heterotrophic bacteria, from 0.6 to $19 \%$ of Synechococcus and from 0.02 to $21 \%$ of Prochlorococcus (Christaki et al., 2001). Some species also graze pico-eukaryotes $(<3 \mu \mathrm{m})$ (Christaki et al., 2005). The latter were partially represented in our system of study within FNs 3 and 28. We included in HNF diet all the food-items listed above, giving much relative weight to trophic links involving prokaryotes. According with meta-analyses, nanociliates (FN 25) are reported to eat preferentially cell preys smaller than $9 \mu \mathrm{m}$ ESD (Sailley and Buitenhuis, 2014). As an example, the prostomatid Uronema spp. (included in FN 25) eats preferentially more Synechococcus than Prochlorococcus and heterotrophic bacteria (Christaki et al., 1999).

Larger ciliates, such as prostomatids and Strobilidium spp. (average ESD $\sim 54 \mu \mathrm{m}, \mathrm{FN} 22,36$ and FN 23, 37, respectively), could ingest all unicellular plankters, from bacteria to ciliates (Sailley and Buitenhuis, 2014) but should prefer food items having an ESD $>12 \mu \mathrm{m}$ (Jeong et al., 2002). Diatoms appeared not to be selected by the above-mentioned organisms probably because these microalgae would provide low quality food to ciliates (Müller and Schlegel, 1999). Tintinnids ingest particles whose size is around $43 \%$ of the diameter of lorica at the oral opening (Heinbokel, 1978). The average diameter for tintinnids in the GoN (FN 24), weighted to each species' relative abundance, is about $20 \mu \mathrm{m}$ and the probable maximum size of prey edible by tintinnids in our food-web should be $9 \mu \mathrm{m}$. In the laboratory, tintinnids consuming phytoflagellates (FN 12) grew at the same rates than those fed with diatoms lacking significant external processes (FN 7) (Verity and Villareal, 1986). Moderate growth was observed when tintinnids ate small dinoflagellates (FN 14) while extensive mortality was reported in tintinnids fed with Synechococcus (FN 1) (Verity and Villareal, 1986).

\section{Heterotrophic metazoans}

In the following paragraphs, literature references and specific rationales for the calculation of production, consumption, assimilation rates and the definition of diets of metazooplankton (Tab. 4, Figs. 4 and 5) are provided. Planktonic metazoans in our food-web include a large va- riety of groups and species with remarkably different life history traits and individual performances.

\section{Production rates}

Among marine cladocerans, Penilia avirostris (FN 42) which was extensively studied in the Mediterranean Sea and along Brazilian coasts, showed max growth rates higher than 1.0 day $^{-1}$, thus comparable to that of microbes (Atienza et al., 2007, 2008; Egloff et al., 1997). This species is characterized by intense population bursts pursued by fast parthenogenetic reproduction, especially during summer (Atienza et al., 2007, 2008). In cladocerans, juveniles differ from adults only for their smaller size and occupy a niche comparable to the adult stage, which is reached very rapidly (<3 days) (Egloff et al., 1997). In the studied food-web, the minimum-maximum values of production rates for $P$. avirostris were set assuming that population increasing dependended only on i) the animal birth rate, and ii) the hatching of parthenogenetic eggs', without considering somatic growth. Moreover, since the relation between population growth rates and food environment for cladocerans is still unknown, a single range of production rate, derived from the above-mentioned studies, was considered for both the Green and Blue states. Scanty information is available in the literature for the cladocerans Evadne spp. and Pseudevadne tergestina (FN 43) and we assumed that minimum-maximum production rates for these animals were the same of those set for $P$. avirostris, in both the Green and Blue states.

Unlike cladocerans, the copepod life-histories include several developmental stages. Both population and individual growth rates are good proxies of these animals' productivity (Frangoulis et al., 2010). We used the weight-specific fecundity to define production rates for adults, assuming that adult-female production is completely realized by means of egg production (Hirst and Bunker, 2003) without any change in individual biomass at short-time scales. Conversely, the weight-specific (somatic) growth was used to define production rates in juvenile copepods, since they undergo changes in individual biomass at short time-scales (Hirst and Bunker, 2003). Production rates for both adult and juvenile copepods in our case-study were based on the extensive synopsis of growth rates of copepods published by Hirst and Bunker (2003), which linked growth rates to i) species body-mass, ii) temperature and iii) food concentration. Since copepods in our case-study were sampled in the upper $50 \mathrm{~m}$ layer of the water column, we set minimummaximum values as the rates predicted for temperatures and food conditions present in the environment at the surface and at the bottom of the sampling layer in the Green and Blue states ( $\mathrm{T}$ ranging $25-15^{\circ} \mathrm{C}$ and food ranging 203-21 and 37-17 $\mathrm{mg} \mathrm{C} \mathrm{m}^{-3}$ at Green and Blue states, respectively). Growth rates of copepods (FN 44-49) were 
well below those reported for cladocerans (Fig. 4, Tab. 4).

Pelagic tunicates, represented by appendicularians, doliolids and salps in our case-study (FN 50-52), are semelparous organisms - i.e., they reproduce only once in a lifetime and die after reproducing (Bone, 1998). Moreover, pelagic tunicates have no larval stage and newly born individuals are comparable to adults in terms of feeding performances, ecological role and, in some cases, body-size (Bone, 1998; Deibel and Lowen, 2012 and references therein). Adults undergo also an intense somatic growth, which must be considered when parameterizing the production rates of these animals. The growth rate of pelagic tunicates is represented by the so-called 'lifetime fitness', a parameter that in population ecology studies is a synonym of 'recruitment' (Deibel and Lowen, 2012). The lifetime fitness integrates both the timing of egg release and the somatic growth that precedes spawning and it expresses the maximum intrinsic rate of natural increase. Taking into account the short duration of life-cycle of pelagic tunicates and the time scale of our case-study, we considered the lifetime fitness as thoroughly suitable to represent production rates of pelagic tunicates in unit of biomass.

Oikopleura dioica was the main appendicularian species present in the GoN during summer and it is included herein within FN 50. A life-cycle-based model demonstrated that lifetime fitness of this species was strongly influenced by both temperature and food concentration (Lombard et al., 2009b; Deibel and Lowen, 2012). Alike other pelagic tunicates, appendicularians are sensitive to high food concentrations: i.e., they easily undergo super-saturation/engulfment, with negative effects on reproduction at food concentration $>300 \mathrm{mg} \mathrm{C}$ $\mathrm{m}^{-3}$ (Lombard et al., 2009b). However, in our system, food availability did not exceed $200 \mathrm{mg} \mathrm{C} \mathrm{m}^{-3}$. The range of production rate of appendicularians in our casestudy was set based on the studies above (with maximum $=1.13 \mathrm{~d}^{-1}$ ).

Growth rates of doliolids were studied less extensively than those of appendicularians. In our case-study, the genus Doliolum was the most represented doliolid in the GoN during summer (FN 51), mainly with the species $D$. nationalis. A lifetime fitness of $0.26 \mathrm{~d}^{-1}$ at $20^{\circ} \mathrm{C}$ was estimated for D. gegenbauri (Deibel and Lowen, 2012), featuring also a slight dependence from the food concentrations (Gibson and Paffenhöfer, 2000). Assuming a linear dependence between temperature and growth rates in the range of $15-25^{\circ} \mathrm{C}$, this parameter would be $0.20-0.33 \mathrm{~d}^{-1}$ between 15 and $25^{\circ} \mathrm{C}$ (based on $\mathrm{Q}_{10}$ assumed for pelagic tunicates, according to Broms and Tiselius, 2003). We assumed the lowest number in the above-mentioned range as the minimum production rate for doliolids in our system. This rate would refer to the complete lifecycle of $D$. gegenbauri (encompassing up to six different life stages). Yet, $D$. nationalis is characterized by a bi-phasic life-cycle in which asexual production of new individuals can strongly shorten the generation time (Godeaux et al., 1998). To the best of our knowledge, no estimation of growth rates for D. nationalis has been carried out so far. We thus assigned a maximum production rate of $\sim 1.9$ $\mathrm{d}^{-1}$ to doliolids, which is a value similar to that reported for salps (Madin and Deibel, 1998).

Salps have both sexual and asexual reproduction in their life cycle (Bone, 1998). Scanty information is available about growth rates of these animals (FN 52), due to the difficulty to breed them in laboratory at controlled conditions. Thalia democratica was the most represented species in the GoN during summer. The lifetime fitness of this species reported in the literature ranged 0.18-1.9 $\mathrm{d}^{-1}$, within a temperature range of $14-22^{\circ} \mathrm{C}$ (Deibel and Lowen, 2012 and references therein). Interestingly, temperature does not seem to affect salp growth rate, based on the data available. Also, the lower rates were measured in the lab, while the highest ones were estimated from the field. While fast growth (up to $1.9 \mathrm{~d}^{-1}$ ) could theoretically occur only in particular circumstances, such as the still poorly explained massive outbreaks occurring in nature (Deibel and Lowen, 2012 and references therein), slower growth was probably due to the confinement of large animals in a limited space in the laboratory. Based upon the se considerations, we considered the whole range of variability of salps lifetime fitness.

In our case-study, we included also meroplankton (FN 53), which features planktonic larvae of benthic organisms. We used the rate of somatic growth of larvae as a proxy of production rate for meroplankton at the time scale of our case-study. Growth rates ranging 0.025-0.15 $\mathrm{d}^{-1}$ were reported for larvae of the polychaete Polydora ciliata at $16^{\circ} \mathrm{C}$ in the laboratory (Almeda et al., 2009), with the highest rates attained at food saturation, i.e. about $1 \mathrm{mg} \mathrm{C} \mathrm{L}^{-1}$, a value about double the highest concentration of POC in our study system. After applying a $\mathrm{Q}_{10}$ of 2.8 (Hansen and Bjørnsen, 1997), the rates ranged 0.07$0.42 \mathrm{~d}^{-1}$. Due to the scarce knowledge on the relation between growth, food and temperature in meroplankton, we assigned an identical minimum-maximum production range (0.025-0.42 $\mathrm{d}^{-1}$, respectively) in both the Green and Blue states.

Finally, no information was gathered for the growth rates of chaetognaths, the most abundant carnivorous mesozooplankton group (FN 60) in our case study.

\section{Consumption rates}

Penilia avirostris (FN 42) from the Mediterranean Sea showed in the laboratory weight-specific ingestion rates ranging $0.26-1.57 \mathrm{~d}^{-1}$ in summer conditions (natural photoperiod and temperature $22-27^{\circ} \mathrm{C}$ ) (Atienza et al., 2006). However, a significantly wider range of $0-7 \mathrm{~d}^{-1}$ was re- 
ported at about $22^{\circ} \mathrm{C}$ (Katechakis et al., 2004), with minimum-maximum values corresponding to food concentrations of about 0 and $>250 \mathrm{mg} \mathrm{C} \mathrm{m}^{-3}$ (saturating condition). At food concentration of $203 \mathrm{mg} \mathrm{C} \mathrm{m}^{-3}$, i.e., the maximum food concentration for a metazoan in our case study, the consumption rate should be $3.50 \mathrm{~d}^{-1}$ (recalculated data from Katechakis et al., 2004). Since mesozooplankton in our case-study are likely able to cross the seasonal thermocline, the above mentioned range should be representative for the natural food range in our study system. Based on regression derived from the literature (Katechakis et al., 2004), the minimum-maximum consumption rates should range $0.71-3.5 \mathrm{~d}^{-1}$ in the Green state (i.e., with food concentrations ranging 21-203 $\mathrm{mg} \mathrm{C} \mathrm{m}^{-3}$ ), and $0.65-0.95 \mathrm{~d}^{-1}$ in the Blue state (i.e., with food concentrations ranging $17-37 \mathrm{mg} \mathrm{C} \mathrm{m}^{-3}$ ).

The literature available for the feeding performances of copepods features both in situ and laboratory studies. Various authors have conducted meta-analyses based on published data to search for global relations between feeding rates and i) food concentration, ii) body-mass, and iii) temperature, with the first variable being the main driver of feeding rates of copepods in nature as food concentration can explain $52 \%$ of the variance of ingestion rates (Saiz and Calbet, 2011, 2007). Herein, we derived the most probable values of consumption rates for the main calanoid copepods in our case-study by using multiple regression relations between ingestion rates and the main driving factors, as described in Saiz and Calbet (2011, 2007). Known variables in our calculations were i) FNs' body-mass and ii) the amount of carbon allocated into unicellular FN with ESD $\geq 3 \mu \mathrm{m}$ - i.e., the lowest size of food particles edible by copepods (Bartram, 1981) - in the Green and Blue states and in the surface and deeper layers (i.e., 203-21 and 37-17 $\mathrm{mg} \mathrm{C} \mathrm{m}^{-3}$, respectively). As shown in Fig. 4, these rates were always lower than $0.5 \mathrm{~d}^{-1}$, thus significantly lower than those of most unicellular organisms. Differently from calanoid copepods, ingestion rates of the cyclopoid Oithona spp. (FN 54, including copepodites and adults of different species) were herein based on regression derived from data referring to $O$. davisae at different life stages (Almeda et al., 2010; Saiz et al., 2003). The minimum-maximum consumption rates for this animal were derived at the four key-concentrations considered also for other copepods; Oithona's consumption rates were slightly higher than those for calanoid copepods, although they exceeded to some extent $0.5 \mathrm{~d}^{-1}$ only in the Green state.

The knowledge about trophodynamics of gelatinous filter-feeders presented some discrepancies: although consumption rates were well assessed in the laboratory for appendicularians, the same was not true for doliolids and salps. The ingestion rates of the appendicularian $O$. dioica was described in detail in laboratory conditions $\left(\mathrm{T}=15^{\circ} \mathrm{C}\right)$
(Lombard et al., 2009a, 2009b). Ingestion in these animals was directly related to temperature and inversely related to food concentration. Consumption rates for appendicularians (FN 50) were obtained from published regressions (Lombard et al., 2009a, their Tab. 2), applied at the four key food-concentrations at the two system states (see above). The maximum consumption rate, corresponding to the surface layer, was increased according to a $\mathrm{Q}_{10}$ of 1.78 specific for grazing rates of $O$. dioica (Broms and Tiselius, 2003). According to our recalculations, a maximum consumption rate of more than $30 \mathrm{~d}^{-1}$ could be possible in appendicularians in the Green state. Though very high, such rate is not improbable, considering the low body-mass of these gelatinous filter feeders and the possibility to eliminate the food in excess by abandoning engulfed houses (Bone, 1998).

Concerning other gelatinous filter-feeders, the ingestion rate in relation with food concentrations was described in detail for Doliolum denticulatum from the North Western Mediterranean at laboratory conditions and using a natural microplankton community as food (Katechakis et al., 2004). The animals used in the above-mentioned study had a size comparable to that of $D$. nationalis. The range of consumption rate of doliolids in our study case (FN 51, with maximum value up to $8 \mathrm{~d}^{-1}$ in the Green state, Fig. 4C,D) were based on regressions derived from the study above and applied at the four key food concentrations for metazooans in our study-case (see above). Ingestion rates of salps (FN 52) were scarcely investigated in comparison with other gelatinous filter feeders. Individuals of salps $<10 \mathrm{~mm}$ in size (the individual size more frequently found in samples collected at station LTER-MC) showed weight-specific ingestion rates ranging $2-8.3 \%$ of the body carbon per hour, i.e., $\sim 0.24-1 \mathrm{~d}^{-1}$, assuming that an individual feeds at least for $12 \mathrm{~h}$ a day (Madin and Deibel, 1998). This range is similar to the one observed in nature in the Southern Ocean at temperature $<15^{\circ} \mathrm{C}$, i.e., $0.1-1 \mathrm{~d}^{-1}$ (von Harbou et al., 2011). Assuming that a $\mathrm{Q}_{10}$ of 1.78 was applicable to salps as for appendicularians (Broms and Tiselius, 2003), the maximum consumption rate should be $1.78 \mathrm{~d}^{-1}$ for both the Green and Blue states in the GoN. Thus, salps' consumption rate would range $0.24-1.78 \mathrm{~d}^{-1}$, likely enough to sustain the potentially high production rates of these organisms (Fig. 4). Moreover, since in our study system the concentration of food available to salps always exceeded $10 \mu \mathrm{g} \mathrm{C} \mathrm{L}^{-1}$, i.e., the saturation limit of these animals (Andersen, 1985; Deibel, 1982), we believe that the same value of maximum consumption rate can be applicable to both the Green and Blue states.

Feeding rates of meroplanktonic larvae (FN 53) typically found during summer in the GoN, i.e., polychaets, echinoderms, cirripedes, bivalves and gastropods, were measured over natural microplankton concentrations and 
a specific ingestion rate of $2.5 \mathrm{~d}^{-1}$ was reported for each of these groups (Almeda et al., 2011b). These rates referred to a natural phytoplankton bloom in the Vancouver bay during July with temperature ranging $13-17^{\circ} \mathrm{C}$ and at food concentration of 2-6 $\mu \mathrm{g} \mathrm{Chl} a \mathrm{~L}^{-1}$, thus comparable to the Green state in the GoN in surface waters. Assuming a $\mathrm{Q}_{10}$ of 2.8 (Hansen and Bjørnsen, 1997), the maximum consumption rate during summer in the GoN accounted for $7 \mathrm{~d}^{-1}$, which was a very high rate. However, meroplanktonic larvae have high energetic requirements to pursue an intense somatic growth and such high rates were not improbable. Being information on functional response of meroplankton scarce in the literature, the minimum rate can be only set herein as double the production rate.

Scantier information was available for the other animals in the food-web. Planktonic detritivores in our casestudy (FN 55) included only cyclopoid and harpacticoid copepods whose feeding appendages are suited to scrap food particles from discharged appendicularian houses. Oncaea mediterranea was reported to eat up to $100 \%$ of its body-biomass at $20^{\circ} \mathrm{C}$ (Paffenhofer, 1993). According to the regression described by Saiz and Calbet (2007), the maximum potential consumption rate for these animals should be $1.23 \mathrm{~d}^{-1}$ in our case study and considering their body-size. The minimum consumption was assumed as $\sim 0.1 \mathrm{~d}^{-1}$, a value similar to the minimum ingestion rate of other copepods.

Finally, the ingestion rate of carnivores (FN 56) was assumed as driven mainly by that of chaetognaths. Different Sagitta species were studied at different maturity stages and across a coast-offshore trophic gradient in the Western Mediterranean during summer (Duró and Saiz, 2000): in that study, between 0.13 and 3.76 preys were ingested per chaetognath per day and no relation with food concentration was recorded. In our system, considering an average weight of $18.35 \mu \mathrm{g} \mathrm{C}$ per animal/prey for the FNs potentially eaten by chaetognaths, consumption rate of these predators should range $0.013-0.37 \mathrm{~d}^{-1}$, both in the Green and Blue states.

\section{Assimilation rates}

In the literature, mesozooplankton were reported to have variable assimilation efficiency values, depending upon the actual food environment. Synthetic data are shown in Tab. 4. The assimilation efficiency of cladocerans (FN 42-43) was ranged 0.70-0.45 from lowest to highest food concentrations, respectively, within the range of variability of our study system (Katechakis and Stibor, 2004; Katechakis et al., 2004). The assimilation efficiency of calanoid copepods (FN 44-48) was set based on the information available for $A$. clausi, which showed assimilation efficiency ranging $0.78-0.45$, within a wide range of food concentrations from $\sim 0$ to over $800 \mu \mathrm{g} \mathrm{C} \mathrm{L}^{-1}$ (Katechakis et al., 2004). Yet, the relation between assimilation effi- ciency and food concentration was not statistically significant (Katechakis et al., 2004), since some values were comprised between 0.6 and 0.8 at super-saturating food concentrations. In the range of food variability of our study system, and considering a linear regression fitting datapoints, assimilation efficiency would range $\sim 0.68-0.40$, for both the Green and Blue states. This range was considered valid for all calanoid copepods (FN 44-48) excepting juvenile stages (FN 49, including mainly copepodites). The assimilation efficiency for the latter was a fixed value of 0.73 , assuming that it was equal to that of $O$. davisae juveniles at $20^{\circ} \mathrm{C}$ (Almeda et al., 2011a). Higher assimilation in juveniles is likely due to the need to sustain a strong somatic growth, which is absent in adults. Concerning the cyclopoid copepod Oithona spp., assimilation efficiency ranged 0.65-0.76 in different life stages of Oithona (FN 54) (Almeda et al., 2011a). Considering that Oithona spp. are ambush feeders, the saturation likely emerges at concentrations higher than those critical for suspension feeders, thus giving a relatively narrower assimilation efficiency range. Concerning detritivores, assimilation efficiency can be assumed equal to that of Oithona.

In comparison with copepods, the assimilation efficiency (and, in general, the feeding dynamics) of gelatinous mesozooplankton is more influenced by external conditions. Assimilation efficiency of appendicularians (FN 50) was strongly and inversely related to food concentration (Lombard et al., 2009a, 2009b). A regression linking assimilation efficiency to food concentration was used to infer values relating to concentration and temperature extremes in our study-system (recalculated data from Lombard et al., 2009a, 2009b), considering also a $\mathrm{Q}_{10}$ of 1.78 as reported by Broms and Tiselius (2003). In our system, assimilation efficiency for appendicularians ranged 0.40-0.91 in the Blue state, and 0.06-0.91 in the Green state, with relatively higher values at lower food concentrations. Assimilation efficiency for doliolids (FN 51) ranged $0.32-0.72$ in the range of food concentration of our study system (Katechakis et al., 2004). Using the regression described by Katechakis et al. (2004), this parameter ranged 0.42-0.72 and 0.32-0.72 in the Blue and Green states, respectively. Assimilation efficiency of salps (FN 52) within $10 \mathrm{~mm}$ in length (like in our case-study) should be around 0.67 (Pakhomov, 2004), and this value was comparable to estimations made during an iron fertilization experiment, when assimilation efficiency ranged 0.75-0.87 at two fairly distant carbon concentrations (von Harbou, 2010). We can thus hypothesize that stable assimilation efficiency for salps, likely also at 'our' Green and Blues states, can stem from the regulation of feeding by eliminating water and food in excess by means of backwashing (Madin and Deibel, 1998).

Carnivorous mesozooplankton (FN 56), mainly chaetognats in our case-study, were reported to have as- 
similation efficiency ranging $0.80-0.82$ (Cosper and Reeve, 1975; Giesecke et al., 2010). These rates were similar to those reported for siphonophores (Purcell and Kremer, 1983), other strictly carnivorous zooplankters occurring sporadically in our system, and we considered them valid in both the Green and Blue states. No information was available for meroplankton and detritivores (FN 53 and 55, respectively). About the former animals, we can assume a fixed assimilation efficiency of 0.8 in both the Green and Blue states, since larvae should convert in somatic growth a large part of the ingested food.

\section{Diet}

This paragraph describe in detail the derivation of values included in Fig. 5. The trophic links presented herein are considered valid for both Green and Blue states.

Unlike protistan grazers, mesozooplankton in our case-study were supposed to be eating in both surface and deeper water- layers. Cladocerans (FN 42-43) are suspension feeders: i.e., their food particles are conveyed to oral apparatus by feeding currents produced by their appendages. Among cladocerans, $P$. avirostris (FN 42) was reported to eat plankton particles of size $\geq 1 \mu \mathrm{m}$, i.e., the size of cyanobacteria and prochlorophytes, although flagellates, diatoms and dinoflagellates appeared to be the preferred preys (Atienza et al., 2006). Yet, ciliates tended to be excluded due to their motility and larger size (Atienza et al., 2006). When considering the size-spectra, the highest selectivity was detected for food particles between 15 and $70 \mu \mathrm{m}$ in size, corresponding to $6-28 \mu \mathrm{m} \mathrm{ESD}$, and decreased for values outside this size range (Katechakis et al., 2004). Evadne, another cladoceran genus present in the GoN (FN 43), seemed to prefer food particles with an ESD between 40 and $60 \mu \mathrm{m}$, different from those selected by Penilia (Katechakis and Stibor, 2004).

The majority of calanoid copepods present in the GoN during the time period object of this study were suspension feeders reported to eat mainly unicellular organisms, with the exception of prokaryotes. Paracalanus spp. (FN 44) was reported to collect relatively small particles $(<5 \mu \mathrm{m}$, ESD $2 \mu \mathrm{m}$ ) only passively (Price et al., 1983) and animals under laboratory conditions appeared to select for mediumsized diatoms ( $<30 \mu \mathrm{m}$ in length) when exposed to a mixeddiatoms diet (Mahadik, 2014). Acartia clausi (FN 45) was reported to eat particles between 7.5 and $210 \mu \mathrm{m}$ in size, to select cells ranging 70-100 $\mu \mathrm{m}$, and to neglect particles $<7.5 \mu \mathrm{m}$ (Katechakis et al., 2004). Within the size-limits of ingestion, the selectivity observed in A. clausi matched always the peak of available food particles (Katechakis et al., 2004). This species feeds also on protozooplankton (Fileman et al., 2010), being able to switch from a suspension to an ambush feeding (Saiz and Kiørboe, 1995) as its congeneric species $A$. tonsa (Kiørboe et al., 1997).

The lower size of plankton particles eaten by the cruiser/suspension-feeder Temora stylifera (FN 46) seemed larger than that for A. clausi (Dam, 1986). Individuals of T. stylifera from the GoN selected mainly cells and colonies ranging 30-200 $\mu \mathrm{m}$ when offered diatoms (Mahadik, 2014). Centropages typicus (FN 47) was reported to eat a wide array of organisms: small algae (Tomasini and Mazza, 1979), large ciliates or dinoflagellates (Calbet et al., 2007), appendicularian juveniles and eggs (López-Urrutia et al., 2004) and juvenile copepods (Titelman, 2001). The lower size-limit of food-items for this species was $10 \mu \mathrm{m}$; yet, the upper size-limit appeared less precise, since C. typicus could ingest prey larger than its own size (e.g., yolk-sac fish larvae, Calbet et al., 2007 and references therein). Indeed, C. typicus was reported to behave both as a cruiser (and suspension feeder) and as an ambush predator, thus selecting for large motile preys. Stable Isotope Analyses showed recently that Acartia, Centropages, Paracalanus and Temora in the Tyrrhenian Sea had behaved as herbivorous or omnivorous according to different areas (Rumolo et al. 2016). Different species of calanoid copepods of the genera Clausocalanus and Paracalanus were aggregated in the present study (FN 48). These genera being morphologically and dimensionally similar, we roughly assumed that their diets overlapped that of P. parvus (FN 44), though their different swimming behaviours indicate differences in particle capture (Mazzocchi and Paffenhöfer, 1999; Paffenhöfer, 1998). The trophic behavior of juveniles of calanoid copepods (FN 49, including mainly Paracalanus and Clausocalanus in our study system) was considered similar to that of adults of P. parvus.

Species of the genus Oithona were the most numerous cyclopoid copepods in our system and period of study. It was estimated that the daily ration of these animals came for the $20-30 \%$ from faecal pellets (Gonzalez and Smetacek, 1994) and for at least $25 \%$ from copepod juveniles (Lampitt, 1978). Moreover, ciliates represented preferred preys among microplankton and accounted for at least the $25 \%$ of the daily ration (Castellani et al., 2005). In some cases, ciliates and dinoflagellates represented up to $80 \%$ of Oithona diet (Castellani et al., 2008). Considering the percentages above, ciliates and dinoflagellates should not contribute less than $40 \%$ of the daily ration of Oithona spp. Concerning phytoplankton, only particles larger than $10 \mu \mathrm{m}$ were reported to be eaten by Oithona spp. (Drits and Semenova, 1984), and these food particles should not contribute more than $10 \%$ of the daily ration of this copepod genus.

Three categories of non-selective filter-feeding animals were considered in our case-study: appendicularians, doliolids and salps (Bone, 1998). Appendicularians ingest a wide spectrum of particulate material, including bacteria and microzooplankton. Although these animals would not select for food particles, specimens belonging to the genus 
Oikopleura showed the highest uptake for particles with ESD ranging 20-60 $\mu \mathrm{m}$ (Vargas and González, 2004). Moreover, ingestion of eukaryotes with ESD $<13 \mu \mathrm{m}$ was reported as almost three times higher than that of smaller prokaryotes (Scheinberg et al., 2005). Deibel (1985) and Madin and Deibel (1998) reported doliolids feeding preferentially on particles $<50 \mu \mathrm{m}$ ESD. Salps are also nonselective feeders eating particles of size larger than doliolids (Madin \& Deibel 1998). Doliolids ingest foodparticle with a size range similar to that of particles eaten by appendicularians. Though, higher selectivity was reported for particles between 2.5-7.5 $\mu \mathrm{m}$ in size, while particles larger than $100 \mu \mathrm{m}$ were not grazed (Katechakis et al., 2004). Selectivity indexes for picoplankton (including bacteria) and for microplankton between 15 and $100 \mu \mathrm{m}$ were half the maximum (Katechakis et al., 2004). However, they have been recently reported to have high affinity for particles with size $<3 \mu \mathrm{m}$, i.e., bacteria, virus and colloids, which could be an important source of food at low microplankton concentration (Sutherland et al., 2010). Indeed, in the course of a feeding experiment in which animals were fed with microspheres, about $60 \%$ of particles found in the gut were within $1 \mu \mathrm{m}$ in size at concentrations in the order of $10^{3}$ cell $\mathrm{mL}^{-1}$, thus comparable to those found in our system at any state and depth of the water column (Sutherland et al., 2010). Though flagellates and small diatoms $(>1 \mu \mathrm{m})$ might represent a larger carbon-pool in nature due to their abundance, prokaryotes and smaller particles $(0.1-1 \mu \mathrm{m})$ are easier to be digested than larger microbes since they show a relatively high surface area to volume ratio.

Meroplankton were reported to eat different kinds of particles, e.g., nanoflagellates (both auto- and heterotrophic), diatoms, dinoflagellates (of different sizes) and ciliates (Almeda et al., 2011b). Finally, in our casestudy, we assimilated the diet of carnivores (FN 56) to that of chaetognaths. Copepods were the most abundant prey among those identified in the gut of these animals, while cladocerans were ten times less abundant (Duró and Saiz, 2000). Among copepods, larger animals (i.e., C. typicus, T. stylifera, Candacia spp., Pleuromamma spp.) were more oftencaptured than smaller ones (Paracalanus spp., Acartia spp., Clausocalanus spp.). Other crustaceans and chaetognats were also present in the diet, but at lower abundance.

\section{Synthetic characterization of the Green and Blue plankton food-web}

The production rates of organisms in our model system are collectively presented in Fig. 4. Both minimum and maximum values of production rates are included, in order to provide evidence about the variability of these rates. Despite overlapping ranges of production rates pertaining to distant species (in terms of both dimension and evolution- ary history), a decreasing trend of maximum values of production rate with increasing size, which is not unexpected for plankton (Kiørboe and Hirst, 2014) was detected (Fig. 4 A,B). Yet, minimum values appeared less affected by individual size, especially at the Blue state (Fig. 4 A,B). The highest correlation was found for the Green dataset, with a statistically significant inverse correlation between production rates and size $(\mathrm{r}=-0.7 ; \mathrm{P}<0.001)$.

The minimum and maximum values of consumption rates for protozooplankton and metazoan grazers are presented in Fig. 4C,D. The only variations between minimum and maximum values between Green and Blue states were recorded for metazoans. The resolution gained in studies regarding feeding performances of protozooplankton was not high enough to define distinct ranges between Green and Blue conditions. No particular trend of consumption rates per unit of biomass vs. individual size was apparent in the plankton community that we studied (Fig. 4C,D).

All trophic combinations within a hypothetical plankton food-web derived for our case-study are presented in Fig. 5. In this figure we provide a tentative diet-matrix that includes also selective preferences among the fooditems pertaining each consumer. This 'semi-quantitative' elaboration was obtained from a thorough revision of the literature (see previous sections). However, a degree of uncertainty never less than $5 \%$ should be considered as affecting the relative weight of trophic links. In the present form, a single elaboration of food-web was provided, which is representative of both Green and Blue states. Indeed, the production of distinct food-webs for each state was not possible without using network approaches weighting trophic fluxes based on the biomass present at each node. This issue has been discussed in the modelling exercise carried out in D'Alelio et al. (2016). In the present work, we only extrapolated the trophic diversity present into a coastal plankton food-web, based on the organisms that were detected at LTER-MC.

A wide array of trophic connections involved both unicellular and multicellular organisms, and cases of specialized feeding were rare, although present in both groups of organisms. For instance, M. rubrum appeared to feed mainly small cryptophytes (size $<10 \mu \mathrm{m}$, grouped in FN 12) (Crawford, 1989; Gustafson et al., 2000; Johnson and Stoecker, 2005; Johnson et al., 2013; Stoecker et al., 2009). According to predator-prey size ratios, mixotrophic ciliates (ESD 30-40 $\mu \mathrm{m}$ ) could eat from bacteria to the largest ciliates (Sailley and Buitenhuis, 2014). Nonetheless, the fact that this species keeps functional ingested plastids should drift predation mainly towards autotrophic taxa, such as prasinophytes, cryptophytes, haptophytes and chlorophytes (Stoecker et al., 2009 and references therein). Another example of specialized trophic connection is that of cyclopoid and harpacticoid copepods (within FN 55) that are mainly 
reported as scrapers of Appendicularia houses (Paffenhofer, 1993).

A Principal Component Analysis, carried out using all data in Tabs. 2 to 4, showed that most variance in the vital rates was generated by the maximum values of consumption rates, in the Green more than in the Blue state. Primary producers constituted the only homogeneous group in the PCA output, while metazoan filter feeders were the most heterogeneous group (Fig. 6A). In a second analysis, we excluded primary producers (the most homogeneous group), filter feeders (the most heterogeneous group) and bacteria, while we included only protozooplankton and metazoans. The first two PCA components explained 89 and $6 \%$ of the variance, respectively (Fig. 6B). The first component was affected mainly by maximum consumption rates, the second by maximum production rates. In plot in Fig. 6, nodes having similar biological characteristics (i.e., a priori defined trophic guilds, such as suspension feeders, mixotrophic protozooplankton, heterotrophic protozooplankton) were represented with the same colour and included in the same polygon. As shown in Fig. 6, each polygon included a heterogeneous group of data-point in terms of their position in the two-dimensional space. Some omnivorous mesozooplankton (mainly copepods, FN 4449 and 54) formed a somewhat defined cluster but other mesozooplankton organisms, such as cladocerans, were instead closer to protistan consumers. A wide overlapping was recorded between mixo- and heterotrophic protists from the deeper layer. Finally, a strong expansion in terms of ranges of consumption rates affected each a-prori defined guild. In synthesis, the PCA suggested the existence of planktonic 'meta-guilds' including distantly related organisms, such as protozooplankton and metazoans, and supported the view that trophic guilds should not be defined a-priori in a plankton community.

The virtual plankton food-web presented herein includes a total of 817 links distributed among the 63 FNs organized hierarchically from primary producers to carnivorous mesozooplankton (Fig. 7). This network includes links valid for both Green and Blue states, since it was not possible to produce distinct food-webs for either states with the approach used in the present paper. However, the analyses carried out by D'Alelio et al. (2016), which used weighted-network models, suggested that the $95 \%$ of the link present in the present work could be present at both Green and Blue states, despite the fairly distant

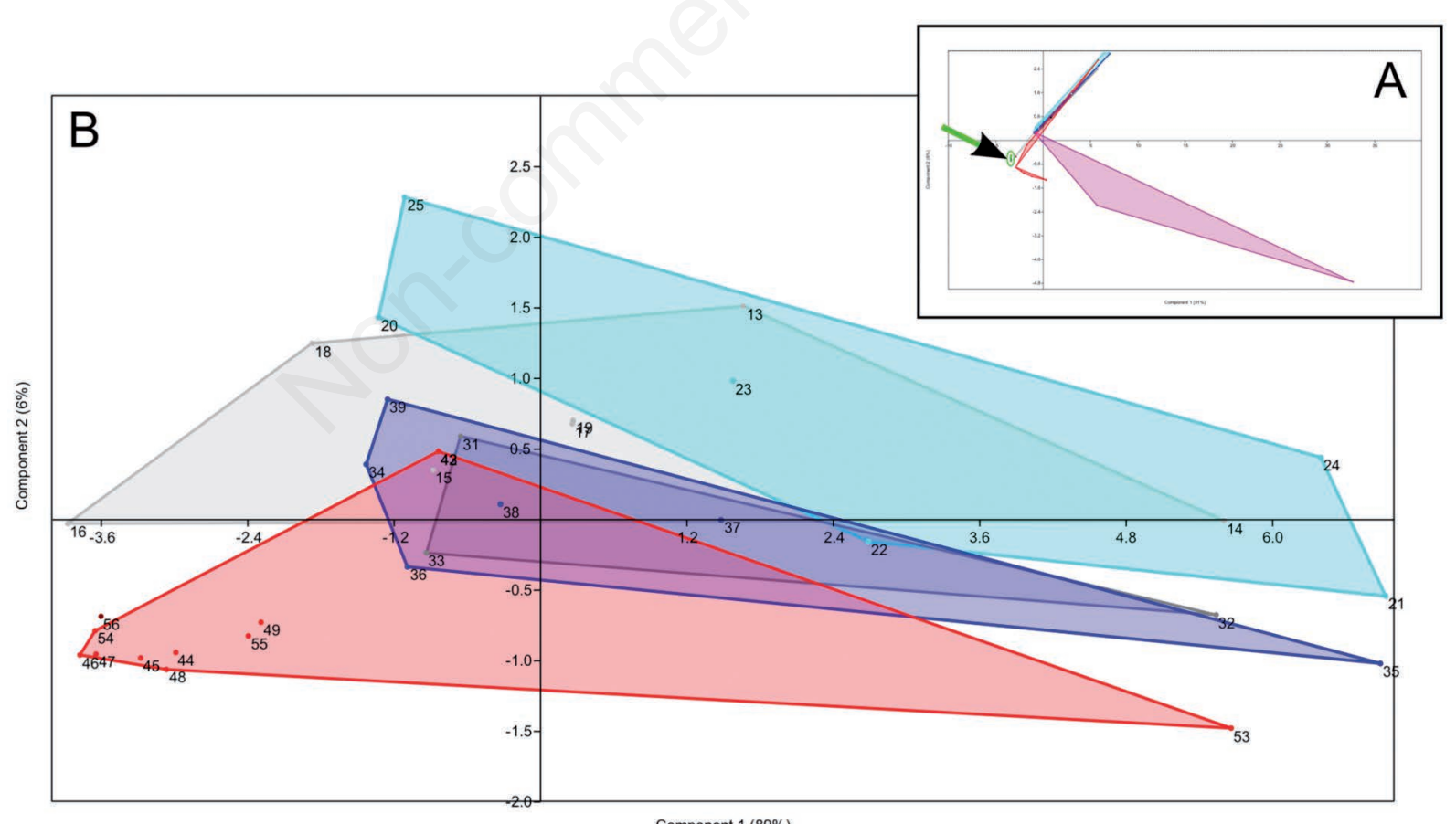

Fig. 6. PCA analysis based on plankton vital rates. The analysis was based on data presented in Tabs. 2 to 4 . A PCA including all nodes and related vital rates is shown in panel A. Therein, the arrow indicates the cluster including primary producers, while the pink polygon connects filter-feeding metazoans. In panel B, a higher-resolution PCA, excluding primary producers and filter-feeders, is presented. The red polygon connects suspension feeding metazoans (cladocerans and copepods). The bright and dark gray polygons connect mixotrophic protists in either the surface or deeper layers, respectively. The bright and dark blue polygons connect heterotrophic protists in either the surface or deeper layers, respectively. Numbers indicate functional nodes (see Tab. 1). 
conditions of overall biomass at the primary producers' level. The main picture shown in Fig. 7 translates into a connectance of 0.21 , which is lower than that reported in a previous network study on the same GoN's plankton community (D'Alelio et al., 2015), in which a connectance of $\sim 0.30$ was derived from time-trends of abundances of most nodes considered in the present paper. Links in trophic (this paper), association (D'Alelio et al., 2015) and biomass-flow (D'Alelio et al. 2016) networks showed a power-law distribution across links, sensu Bascompte and Stouffer (2009), with few nodes (mainly protozooplankton and mesozooplankton filter-feeders) much more connected than others. This observation calls for further studies to clarify the dynamics of aggregation of plankton community as driven by the organization of the network of trophic links.

\section{Plankton trophic links within biogeochemical and fishery models}

The integrative analysis presented in this paper enabled us to i) gain a synthetic view of our system in terms of trophic processes, and ii) compare the overwhelming trophic diversity existing within plankton with the conceptual setting adopted in the most used modelling approaches to aquatic systems. In our opinion, plankton models could potentially benefit from the integration of the trophic diversity shown in the present paper: first, by using more realistic rates, not in absolute terms, but relative to differences existing among consumers; second, by better defining trophic roles of consumers in the planktonic web. Indeed, organisms switch among different prey items or, more in general, among resources. This makes the food-web 'plastic'. Such plasticity can affect system functioning: e.g., the modulation of trophic interactions drives the 'adaptive' transition among fairly different trophic regimes (D'Alelio et al., 2016). Dissecting food-webs' plasticity is thus a crucial challenge of plankton ecology.

Many ecological models focusing on aquatic systems include trophic links among plankton organisms. For instance, a biogeochemical-flux model focusing on a Mediterraneann site (Auger et al., 2011) included three categories of zooplankton and a diet matrix including three consumers (nano-, micro- and mesozooplankton) and seven preys (bacteria, three phytoplankton categories, nano- and micro-zooplankton and particulate organic mat-

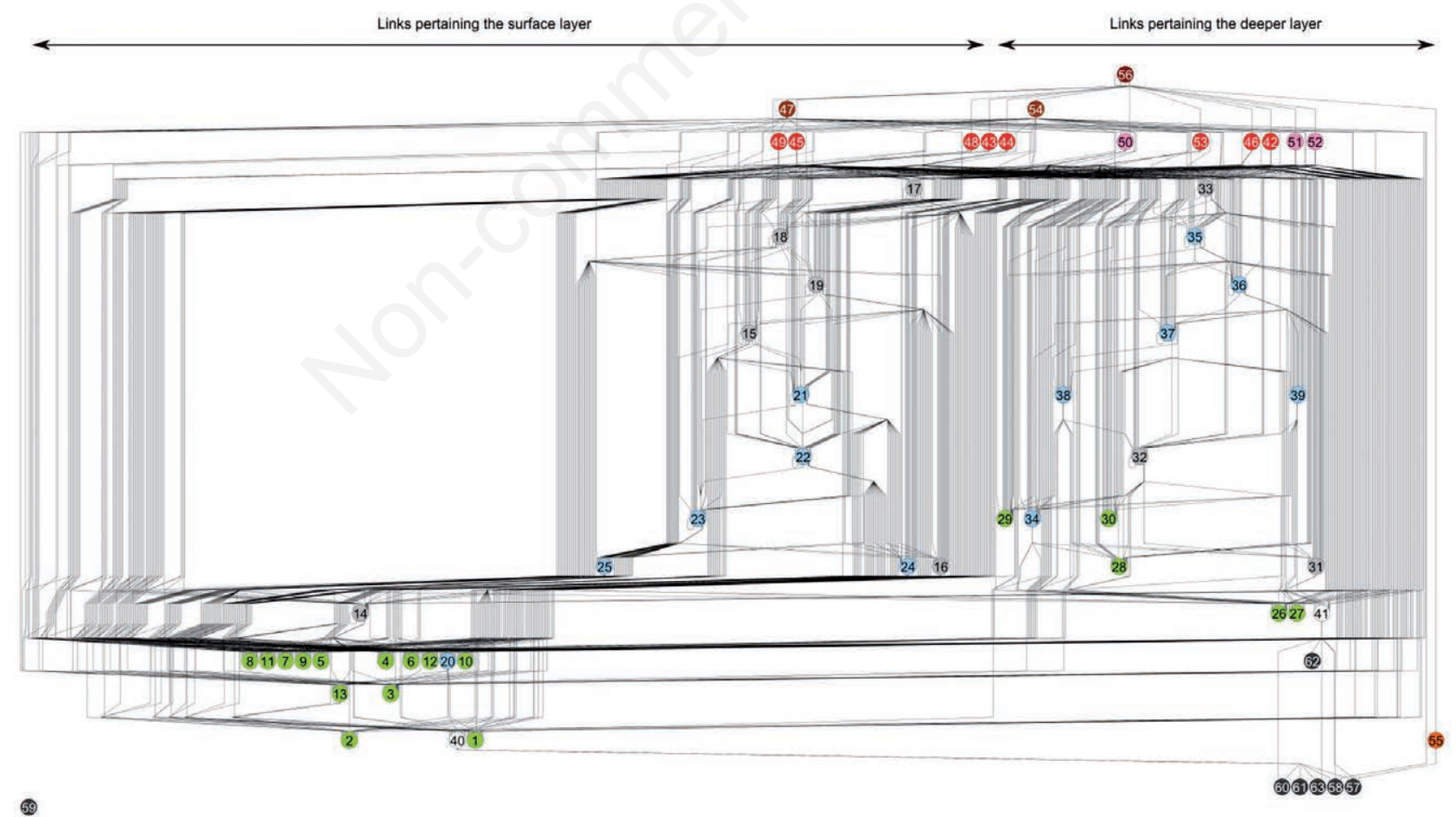

Fig. 7. Virtual plankton food-web. The network was built using links represented in Fig. 5. Red nodes are suspension feeding metazoans. Pink nodes are filter-feeding metazoans. Gray and blue nodes are protist with mixotrophic and heterotrophic metabolism, respectively. Green nodes are primary producers. White and black nodes are bacteria and detritus, respectively. Number at each node refers to FN code (Tab. 1). The network was built using an algorithm that displayed the nodes hierarchically, from the bottom to the top, based on the density of links. Relatively more and less linked nodes set at the bottom and at the top of the web, respectively. 
ter, see Tab. A6 in Auger et al., 2011). Being aware of the fact that the above-mentioned paper was focused on the large-scale dynamics of biogeochemical processes more than on the actual plankton food-web, we try to make some comparisons. The diet-matrix presented by Auger et al. (2011) showed a connectance of 0.24 , but it is scarcely comparable with that reported herein (Figs. 5 and 7). For instance, mesozooplankton, was enabled to eat only phyto- and nano-/microzooplankton, thus excluding the possibility of 'cannibalistic' (intra-guild) predation, which is however a determinant characteristic of the system (e.g., C. typicus feeding on copepods' juveniles, and the strict carnivory of chaetognats). A further and more important issue concerns the maximum grazing rates per unit of biomass $\left(\mathrm{as} \mathrm{d}^{-1}\right.$ ) assumed in the model by Auger et al. (2011): the magnitude of the rate for micro-zooplankton was $\sim 10 \%$ less of that for nanozooplankton (i.e., 3.63 vs $\left.3.89 \mathrm{~d}^{-1}\right)$, while mesozooplankton rate $\left(0.43 \mathrm{~d}^{-1}\right)$ was $88 \%$ lower than that of microzooplankton. In light of the data compiled in the present paper (see Tabs. 3 an 4), the assumption made by Auger et al. (2011) might lead to significant errors in the estimate of grazing impact. First, some important (in terms of biomass) metazoans, such as Appendicularia, can consume up to four-fold more food than protists, proportionally to the specific body-biomass; second, within protists, also due to mixotrophy, there can be a $98 \%$ variability in the maximum consumption rate, thus exceeding the variability considered in the paper cited above between meso- and microzooplankton. In our opinion, biogeochemical-flux modellers should consider the option of including detailed feeding processes at the level of zooplankton, as already suggested by other authors (Flynn et al., 2013; Mitra et al., 2014).

An approach with a more detailed food-web representation comes from Allometric Trophic Network models (ATN), recently applied to the plankton community from Lake Constance (Boit et al., 2012). That model included 24 nodes and 107 links (connectance 0.19 ) and reproduced with a significant accuracy the observed seasonal dynamics of plankton groups. In ATN models, trophic interactions are parameterised by allometric scaling rules, i.e., based on individual size. However, a limit of this approach is that vital rates are represented by fixed values - namely, larger sizes correspond to lower metabolic rates - despite the large variability of vital rates present in the plankton system. ATN are thus applicable as interpolators of biomass fluxes for those closed systems - such as lakes - in which the mass-balanced budget (e.g., in terms of carbon) can be well assessed and rates can be corrected to realistic values. See, as an example, corrections operated to allometrically-predicted rates for phytoplankton, heterotrophic bacteria and filamentous blue and green algae in Tab. 1 in Boit et al. (2012). In fact, as shown in the present paper (Fig. 4), while plankton production rates are in some way inversely correlated to individual size, the same is not true for consumption rates. Moreover, ATN lack, at the present stage, the inclusion of mixotrophic organisms.

Ecological-network models similar to ATN can be also produced for systems in which the mass-balance is unknown. In fact, the latter can be tested in-silico in the frame of modelling approaches focusing on resourcebased growth and losses due to consumption and metabolic costs. These models are developed in the frame of the 'Ecopath' approach (http://www.ecopath.org/, (Christensen and Walters, 2004)), which is often used to derive biomass fluxes in commercially exploited food-webs (Coll et al., 2008). These are purely trophodynamic models based on trophic links and biomass fluxes among nodes. In Ecopath models, vital rates of each node are derived (also iteratively, via Markov Chain Monte Carlo methods) from the respective ranges in a way that the final matrices guarantee the overall biomass balance of the system, based on the initial distribution of biomass among nodes. Moreover, the Ecopath software enables the definition of autotrophy/heterotrophy ratio in consumer nodes and, in the variant Ecosim of the same package, it permits to run time-simulation of the mass-balanced web. Ecopath models are currently used to model marine food-webs ( $\mathrm{Li}$ bralato et al., 2010) but rarely they included more than three plankton groups. Yet, high resolution Ecopath models for plankton are doable and very informative on the bioenergetics of plankton community (D'Alelio et al. 2016).

\section{CONCLUSIONS}

We performed an extensive review of the plankton literature to provide a compilation of data suitable for implementing food-web models including plankton trophic processes at high taxonomic resolution. Our analysis highlights that the ranges of trophic rates in planktonic organisms are very wide. As a consequence, there should be a wide range of possible rearrangements of fluxes and community structure after a change in external forcing. This implies that a drastic aggregation of taxa will never allow to predict the role of biological diversity on ecosystem functioning.

The compilation of data in the present case-study is particularly useful if applied to ecological network models like those developed into Ecopath approaches (D'Alelio et al. 2016). Being aware that the ranges reported also show that values may change from place to place or from trophic state to trophic state, our compilation is more a proof-of-concept of a procedure than a cookbook for model parameterization. However our tables can be used as a reference for future studies, especially if focused on coastal areas and on the summer season, a period crucial for ecological processes like development of harmful 
algal blooms nearby large coastal towns and recruitment of small pelagic fish eating on plankton and exploited in coastal fisheries.

In conclusion, our reasoned synthesis supports the view that biological complexity and diversity cannot be simplified beyond certain limit, without losing any possibility of understanding of how planktonic systems really work. Our study shows that expanding the biological resolution within biogeochemical models could be feasible, having the proper data inputs. It also calls for further efforts to include into the food-web framework presented herein also larger organisms, like macrozooplankton, which play an important role in transferring energy from the mesozooplankton to high-trophic level consumers.

\section{ACKNOWLEDGMENTS}

We thank all colleagues involved in the LTER-MC program for their collaboration and fruitful discussions. We thank Augusto Passarelli, Ciro Chiaese and Ferdinando Tramontano for their key role in the sampling effort and chlorophyll analyses and the crew of the R/V Vettoria for their assistance at sea. LTER-MC data generation and processing is entirely supported by the Stazione Zoologica Anton Dohrn. The authors thank the Flagship RITMARE - The Italian Research for the Sea - coordinated by the Italian National Research Council and funded by the Italian Ministry of Education, University and Research within the National Research Program 2011-2013 for funding this study via the post-doc fellowship to D.D.A. and grants provided to M.R.d.A.

\section{REFERENCES}

Abarca-Arenas LG, Ulanowicz RE, 2002. The effects of taxonomic aggregation on network analysis. Ecol. Modell. 149: 285-296.

Almeda R, Alcaraz M, Calbet A, Saiz E, 2011a. Metabolic rates and carbon budget of early developmental stages of the marine cyclopoid copepod Oithona davisae. Limnol. Oceanogr. 56:403-414.

Almeda R, Augustin CB, Alcaraz M, Calbet A, Saiz E, 2010. Feeding rates and gross growth efficiencies of larval developmental stages of Oithona davisae (Copepoda, Cyclopoida). J. Exp. Mar. Bio. Ecol. 387:24-35.

Almeda R, Messmer AM, Sampedro N, Gosselin LA, $2011 \mathrm{~b}$. Feeding rates and abundance of marine invertebrate planktonic larvae under harmful algal bloom conditions off Vancouver Island. Harmful Algae 10, :194-206.

Almeda R, Pedersen TM, Jakobsen HH, Alcaraz M, Calbet A, Hansen BW, 2009. Feeding and growth kinetics of the planktotrophic larvae of the spionid polychaete Polydora ciliata (Johnston). J. Exp. Mar. Bio. Ecol. 382:61-68.

Andersen V, 1985. Filtration and ingestion rates of Salpa fusiformis Cuvier (Tunicata, Thaliacea): Effects of size, in- dividual weight and algal concentration. J. Exp. Mar. Bio. Ecol. 87:13-29.

Atienza D, Calbet A, Saiz E, Lopes RM, 2007. Ecological success of the cladoceran Penilia avirostris in the marine environment: feeding performance, gross growth efficiencies and life history. Mar. Biol. 151:1385-1396.

Atienza D, Saiz E, Calbet A, 2006. Feeding ecology of the marine cladoceran Penilia avirostris: natural diet, prey selectivity and daily ration. Mar. Ecol. Prog. Ser. 315:211-220.

Atienza D, Saiz E, Skovgaard A, Trepat I, Calbet A, 2008. Life history and population dynamics of the marine cladoceran Penilia avirostris (Branchiopoda: Cladocera) in the Catalan Sea (NW Mediterranean). J. Plankton Res. 30:345-357.

Auger PA, Diaz F, Ulses C, Estournel C, Neveux J, Joux F, PujoPay M, Naudin JJ, 2011. Functioning of the planktonic ecosystem on the Gulf of Lions shelf (NW Mediterranean) during spring and its impact on the carbon deposition: a field data and 3-D modelling combined approach. Biogeosciences 8:3231-3261.

Baines SB, Pace ML, 1991. The production of dissolved organic matter by phytoplankton and its importance to bacteria: petterns across marine and freshwater systems. Limnol. Oceanogr. 36:1078-1090.

Bartram WC, 1981. Experimental development of a model for the feeding of neritic copepods on phytoplankton. J. Plankton Res. 3:25-51.

Bascompte J, Stouffer DB, 2009. The assembly and disassembly of ecological networks. Philos. Trans. R. Soc. Lond. B. Biol. Sci. 364:1781-1787.

Beckerman AP, Petchey OL, Warren PH, 2006. Foraging biology predicts food web complexity. P. Natl. Acad. Sci. USA 103:3745-9.

Behrenfeld MJ, Boss ES, 2014. Resurrecting the ecological underpinnings of ocean plankton blooms. Ann. Rev. Mar. Sci. 6:167-194.

Boit A, Martinez ND, Williams RJ, Gaedke U, 2012. Mechanistic theory and modelling of complex food-web dynamics in Lake Constance. Ecol. Lett. 15:594-602.

Bone Q, others, 1998. The biology of pelagic tunicates. Oxford University Press Oxford.

Boyce DG, Frank KT, Leggett WC, 2015. From mice to elephants: overturning the "one size fits all" paradigm in marine plankton food chains. Ecol. Lett. 18:504-515.

Broms F, Tiselius P, 2003. Effects of temperature and body size on the clearance rate of Oikopleura dioica. J. Plankton Res. 25:573-577.

Calbet A, Carlotti F, Gaudy R, 2007. The feeding ecology of the copepod Centropages typicus (Kröyer). Prog. Oceanogr. 72:137-150.

Castellani C, Irigoien X, Harris R, Lampitt R, 2005. Feeding and egg production of Oithona similis in the North Atlantic. Mar. Ecol. Prog. Ser. 288:173-182.

Castellani C, Irigoien X, Mayor DJ, Harris RP, Wilson D, 2008. Feeding of Calanus finmarchicus and Oithona similis on the microplankton assemblage in the Irminger Sea, North Atlantic. J. Plankton Res. 30:1095-1116.

Chen B, Landry MR, Huang B, Liu H, 2012. Does warming enhance the effect of microzooplankton grazing on marine phytoplankton in the ocean? Limnol. Oceanogr. 57:519-526.

Christaki U, Giannakourou A, Wambeke FVAN, Grégori G, 
2001. Nanoflagellate predation on auto- and heterotrophic picoplankton in the oligotrophic Mediterranean Sea. J. Plankton Res. 23:1297-1310.

Christaki U, Jacquet S, Dolan JR, Vaulot D, Rassoulzadegan F, 1999. Growth and grazing on Prochlorococcus and Synechococcus by two marine ciliates. Limnol. Oceanogr. 44:52-61.

Christaki U, Vázquez-Domínguez E, Courties C, Lebaron P, 2005. Grazing impact of different heterotrophic nanoflagellates on eukaryotic (Ostreococcus tauri) and prokaryotic picoautotrophs (Prochlorococcus and Synechococcus). Environ. Microbiol. 7:1200-10.

Christensen V, Walters CJ, 2004. Ecopath with Ecosim: methods, capabilities and limitations. Ecol. Modell. 172:109-139.

Chust G, Allen JI, Bopp L, Schrum C, Holt J, Tsiaras K, Zavatarelli M, Chifflet M, Cannaby H, Dadou I, Daewel U, Wakelin SL, Machu E, Pushpadas D, Butenschon M, Artioli Y, Petihakis G, Smith C, Garçon V, Goubanova K, Le Vu B, Fach BA, Salihoglu B, Clementi E, Irigoien X, 2014. Biomass changes and trophic amplification of plankton in a warmer ocean. Glob. Chang. Biol. 20:2124-39.

Coll M, Libralato S, Tudela S, Palomera I, Pranovi F, 2008. Ecosystem overfishing in the ocean. PLoS One 3:e3881

Cosper TC, Reeve MR, 1975. Digestive efficiency of the chaetognath Sagitta hispida Conant. J. Exp. Mar. Bio. Ecol. 17:33-38.

Crawford DW, 1989. Mesodinium rubrum: the phytoplankter that wasn't. Mar. Ecol. Prog. Ser. 58:161-174.

D'Alelio D, Libralato S, Wyatt T, d'Alcalà MR, 2016. Ecological-network models link diversity, structure and function in the plankton food-web. Sci. Rep. 6:21806.

D’Alelio D, Mazzocchi MG, Montresor M, Sarno D, Zingone A, Margiotta F, Saggiomo V, Di Capua I, Franzé G, Ribera d'Alcalà M, 2015. The green - blue swing : plasticity of plankton food-webs in response to coastal oceanographic dynamics. Mar. Ecol. 36:115-1170.

Dam H, 1986. Short-term feeding of Temora longicornis Müller in the laboratory and the field. J. Exp. Mar. Bio. Ecol. 99:149-161.

Deibel D, 1982. Laboratory-measured grazing and ingestion rates of the salp Thalia democratica Forskal and the doliolid Dolioletta gegenbauri Uljanin (Tunicata, Thaliacea). J. Plankton Res. 4:189-201.

Deibel D, 1985. Blooms of the pelagic tunicate, Dolioletta gegenbauri: Are they associated with Gulf Stream frontal eddies? J. Mar. Res. 43(1):211-236. February 1985.

Deibel D, Lowen B, 2012. A review of the life cycles and lifehistory adaptations of pelagic tunicates to environmental conditions. ICES J. Mar. Sci. 69.358-369.

Dolan JR, Pérez MT, 2000. Costs, benefits and characteristics of mixotrophy in marine oligotrichs. Freshwater Biol. 45.227-238.

Drits AV, Semenova TN, 1984. Experimental investigations of the feeding of Oithona similis Claus. Oceanology 24:755759.

Duró A, Saiz E, 2000. Distribution and trophic ecology of chaetognaths in the western Mediterranean in relation to an inshore - offshore gradient. J. Plankton Res. 22:339-361.

Edwards KF, Thomas MK, Klausmeier CA, Litchman E, 2012. Allometric scaling and taxonomic variation in nutrient uti- lization traits and maximum growth rate of phytoplankton. Limnol. Oceanogr. 57:554-566.

Egloff DA, Fofonoff PW, Onbé T, 1997. Reproductive biology of marine cladocerans. Adv. Mar. Biol. 31, 80-167.

Fileman E, Petropavlovsky A, Harris R, 2010. Grazing by the copepods Calanus helgolandicus and Acartia clausi on the protozooplankton community at station L4 in the Western English Channel. J. Plankton Res. 32:709-724.

Flynn KJ, Stoecker DK, Mitra A, Raven JA, Glibert PM, Hansen PJ, Graneli E, Burkholder JM, 2013. Misuse of the phytoplankton-zooplankton dichotomy: the need to assign organisms as mixotrophs within plankton functional types. J. Plankton Res. 35: 3-11.

Frangoulis C, Carlotti F, Eisenhauer L, Zervoudaki S, 2010. Converting copepod vital rates into units appropriate for biogeochemical models. Prog. Oceanogr. 84:43-51.

Franzé G, Modigh M, 2013. Experimental evidence for internal predation in microzooplankton communities. Mar. Biol. 160.3103-3112.

Gibson DM, Paffenhöfer G, 2000. Feeding and growth rates of the doliolid Dolioletta gegenbauri Uljanin (Tunicata, Thaliacea). J. Plankton Res. 22:1485-1500.

Giesecke R, González HE, Bathmann U, 2010. The role of the chaetognath Sagitta gazellae in the vertical carbon flux of the Southern Ocean. Polar Biol. 33:293-304.

Godeaux JEA, Bone Q, Braconnot J-C, 1998. Anatomy of Thaliacea, p. 1-24. In: Q. Bone (ed.), The biology of pelagic Tunicates. Oxford University Press.

Gonzalez HE, Smetacek V, 1994. The possible role of the cyclopoid copepod Oithona in retarding vertical flux of zooplankton faecal material. Mar. Ecol. Prog. Ser. 113: 233-246.

Gustafson DE, Stoecker DK, Johnson MD, Van Heukelem WF, Sneider K, 2000. Cryptophyte algae are robbed of their organelles by the marine ciliate Mesodinium rubrum. Nature 405:1049-1052.

Hansen PJ, Bjørnsen PK, 1997. Zooplankton grazing and growth: Scaling within the $2-2,000-\mu \mathrm{m}$ body size range. Limnol. Oceanogr. 42:687-704.

Heinbokel JF, 1978. Studies on the functional role of tintinnids in the Southern California Bight. 2. Grazing rates of field populations. Mar. Biol. 47:191-197.

Hirst AG, Bunker AJ, 2003. Growth of marine planktonic copepods: Global rates and patterns in relation to chlorophyll a, temperature, and body weight. Limnol. Oceanogr. 48:19882010.

Jakobsen HH, Strom SL, 2004. Circadian cycles in growth and feeding rates of heterotrophic protist plankton. Limnol. Oceanogr. 49:1915-1922.

Jeong H, Yoon J, Kim J, Yoo Y, Seong K, 2002. Growth and grazing rates of the prostomatid ciliate Tiarina fusus on redtide and toxic algae. Aquat. Microb. Ecol. 28:289-297.

Jeong HJ, Du Yoo Y, Kim JS, Seong KA, Kang NS, Kim TH, 2010. Growth, feeding and ecological roles of the mixotrophic and heterotrophic dinoflagellates in marine planktonic food webs. Ocean Sci. J. 45:65-91.

Johnson M, Stoecker D, 2005. Role of feeding in growth and photophysiology of Myrionecta rubra. Aquat. Microb. Ecol. 39:303-312.

Johnson MD, Stoecker DK, Marshall HG, 2013. Seasonal dy- 
namics of Mesodinium rubrum in Chesapeake Bay. J. Plankton Res. 35:877-893.

Katechakis A, Stibor H, 2004. Feeding selectivities of the marine cladocerans Penilia avirostris, Podon intermedius and Evadne nordmanni. Mar. Biol. 145:529-539.

Katechakis A, Stibor H, Sommer U, Hansen T, 2004. Feeding selectivities and food niche separation of Acartia clausi, Penilia avirostris (Crustacea) and Doliolum denticulatum (Thaliacea) in Blanes Bay (Catalan Sea, NW Mediterranean). J. Plankton Res. 26, 589-603.

Kiørboe T, 1997. Small-scale turbulence, marine snow formation, and planktivorous feeding. Sci. Mar., 61 (Supl. 1):141-158.

Kiørboe T, Hirst AG, 2014. Shifts in mass scaling of respiration, feeding, and growth rates across life-form transitions in marine pelagic organisms. Am. Nat. 183:E118-30.

Lampitt RS, 1978. Carnivorous feeding by a small marine copepod. Limnol. Oceanogr. 23:1228-1231.

Libralato S, Coll M, Tempesta M, Santojanni A, Spoto M, Palomera I, Arneri E, Solidoro C, 2010. Food-web traits of protected and exploited areas of the Adriatic Sea. Biol. Conserv. 143:2182-2194.

Link JS, Pranovi F, Libralato S, Coll M, Christensen V, Solidoro C, Fulton EA, 2015. Emergent properties delineate marine ecosystem perturbation and recovery. Trends Ecol. Evol. 30:649-661.

Liu H, Nolla HA, Campbell L, 1997. Prochlorococcus growth rate and contribution to primary production in the equatorial and subtropical North Pacific Ocean. Aquat. Microb. Ecol. 12:39-47.

Lombard F, Renaud F, Sainsbury C, Sciandra A, Gorsky G, 2009a. Appendicularian ecophysiology. I. Food concentration dependent clearance rate, assimilation efficiency, growth and reproduction of Oikopleura dioica. J. Mar. Syst. 78:606-616.

Lombard F, Sciandra A, Gorsky G, 2009b. Appendicularian ecophysiology. II. Modeling nutrition, metabolism, growth and reproduction of the appendicularian Oikopleura dioica. J. Mar. Syst. 78:617-629.

López-Urrutia A, Harris RP, Smith T, 2004. Predation by calanoid copepods on the appendicularian Oikopleura dioica. Limnol. Oceanogr. 49:303-307.

Madin LP, Deibel D, 1998. Feeding and energetics of Thaliacea, p. 81-104. In: Q. Bone (ed.), The biology of pelagic Tunicates. Oxford University Press.

Mahadik GA, 2014. The role of copepod grazing in phytoplankton bloom dynamics: a species-based approach. $\mathrm{PhD}$ Thesys, The Open University London.

Mazzocchi MG, Paffenhöefer G-A, 1999. Swimming and feeding behaviour of the planktonic copepod Clausocalanus furcatus. J. Plankton Res. 21:1501-1518.

Mitra A, Castellani C, Gentleman WC, Jónasdóttir SH, Flynn KJ, Bode A, Halsband C, Kuhn P, Licandro P, Agersted MD, Calbet A, Lindeque PK, Koppelmann R, Møller EF, Gislason A, Nielsen TG, St John M, 2014. Bridging the gap between marine biogeochemical and fisheries sciences; configuring the zooplankton link. Prog. Oceanogr. 129: 176-199.

Novarino G, Oliva E, Pérez-Uz B, 2002. Nanoplankton protists from the western Mediterranean Sea. I. Occurrence, ultrastructure, taxonomy and ecological role of the mixotrophic flagellate Ollicola vangoorii (Chrysomonadidae $=$ Chrysophyceae p.p.). Sci. Mar. 66:233-247.

Paffenhöfer G-A, 1993. On the ecology of marine cyclopoid copepods (Crustacea, Copepoda). J. Plankton Res. 15:37-55.

Paffenhöfer G-A, 1998. On the relation of structure, perception and activity in marine planktonic copepods. J. Mar. Sys. 15:457-473.

Pakhomov EA, 2004. Salp/krill interactions in the eastern Atlantic sector of the Southern Ocean. Deep-Sea Res. Pt. II 51:2645-2660.

Pérez MT, Dolan JR, Fukai E, 1997. Planktonic oligotrich ciliates in the NW Mediterranean: growth rates and consumption by copepods. Mar. Ecol. Prog. Ser. 155:89-101.

Price HJ, Paffenhöfer G-A, Strickler JR, 1983. Modes of cell capture in calanoid copepods. Limnol. Oceanogr. 28:116-123.

Purcell JE, Kremer P, 1983. Feeding and metabolism of the siphonophore Sphaeronectes gracilis. J. Plankton Res. 5: 95-106.

Ribera d'Alcalà M, Conversano F, Corato F, Licandro P, Mangoni O, Marino D, Mazzocchi MG, Modigh M, Montresor M, Nardella M, Saggiomo V, Sarno D, Zingone A, 2004. Seasonal patterns in plankton communities in a pluriannual time series at a coastal Mediterranean site (Gulf of Naples): an attempt to discern recurrences and trends. Sci. Mar. 68:65-83.

Rumolo P, Bonanno A, Barra M, Fanelli E, Calabrò M, Genovese S. Ferreri R, Mazzola S, Basilone G, 2016. Spatial variations in feeding habits and trophic levels of two small pelagic fish species in the central Mediterranean Sea. Mar. Env. Res. 115:65-77.

Sailley SF, Buitenhuis ET, 2014. Microzooplankton functional responses in the lab and in the field. Earth Syst. Sci. Data Discuss. 7:49-167.

Saiz E, Calbet A, 2011. Copepod feeding in the ocean: scaling patterns, composition of their diet and the bias of estimates due to microzooplankton grazing during incubations. Hydrobiologia 666:181-196.

Saiz E, Calbet A, 2007. Scaling of feeding in marine calanoid copepods. Limnol. Oceanogr. 52,:668-675.

Saiz E, Calbet A, Broglio E, 2003. Effects of small-scale turbulence on copepods: The case of Oithona davisae. Limnol. Oceanogr. 48:, 1304-1311.

Saiz E, Kiørboe T, 1995. Predatory and suspension feeding of the copepod Acartia tonsa in turbulent environments. Mar. Ecol. Prog. Ser. 122:147-158.

Scheinberg R, Landry M, Calbet A, 2005. Grazing of two common appendicularians on the natural prey assemblage of a tropical coastal ecosystem. Mar. Ecol. Prog. Ser. 294:201-212.

Schoener D, McManus G, 2012. Plastid retention, use, and replacement in a kleptoplastidic ciliate. Aquat. Microb. Ecol. 67:177-187.

Sosik HM, Olson RJ, Neubert MG, Shalapyonok A, Solow AR, 2003. Growth rates of coastal phytoplankton from time-series measurements with a submersible flow cytometer. Limnol. Oceanogr. 48:1756-1765.

Stich H-B, Lampert W, 1981. Predator evasion as an explanation of diurnal vertical migration by zooplankton. Nature 293 : 396-398.

Stoecker D, Johnson M, de Vargas C, Not F, 2009. Acquired phototrophy in aquatic protists. Aquat. Microb. Ecol. 57:279-310. 
Sutherland KR, Madin LP, Stocker R, 2010. Filtration of submicrometer particles by pelagic tunicates. P. Natl. Acad. Sci. USA 107:15129-34.

Titelman J, 2001. Swimming and escape behavior of copepod nauplii: implications for predator-prey interactions among copepods. Mar. Ecol. Prog. Ser. 213:203-213.

Tomasini JA, Mazza J, 1979. Feeding behaviour of Centropages typicus (Copepoda, Calanoida) in nutritive media containing two algae, and in the presence of nauplii of Artemia sp. J. du Cons. 38.

Vargas C, González H, 2004. Plankton community structure and carbon cycling in a coastal upwelling system. I. Bacteria, microprotozoans and phytoplankton in the diet of copepods and appendicularians. Aquat. Microb. Ecol. 34: 151-164.

Verity PG, 1991. Measurement and simulation of prey uptake by marine planktonic ciliates fed plastidic and aplastidic nanoplankton. Limnol. Oceanogr. 36:729-749.
Verity PG, 1986. Growth rates of natural tintinnid populations in Narragansett Bay. Mar. Ecol. Prog. Ser. 29:117-126.

Verity PG, 1985. Grazing, respiration, excretion, and growth rates of tintinnids. Limnol. Oceanogr. 30:268-1282.

Verity PG, Villareal TA, 1986. The relative food value of diatoms, dinoflagellates, flagellates, and cyanobacteria for tintinnid ciliates. Arch. Protistenkd. 131:71-84.

von Harbou L, 2010. Trophodynamics of salps in the Atlantic Southern Ocean. Phd. Diss., University of Bremen.

von Harbou L, Dubischar CD, Pakhomov EA, Hunt BPV, Hagen W, Bathmann UV, 2011. Salps in the Lazarev Sea, Southern Ocean: I. Feeding dynamics. Mar. Biol. 158:2009-2026.

Weisse T, 1997. Growth and production of heterotrophic nanoflagellates in a meso-eutrophic lake. J. Plankton Res. 19:703-722.

Yih W, Kim H, Jeong H, Myung G, Kim Y, 2004. Ingestion of cryptophyte cells by the marine photosynthetic ciliate Mesodinium rubrum. Aquat. Microb. Ecol. 36:165-170. 